\title{
Near-infrared remote sensing of Los Angeles trace gas distributions from a mountaintop site
}

\author{
D. Fu ${ }^{1,2}$, T. J. Pongetti ${ }^{1}$, J.-F. L. Blavier ${ }^{1}$, T. J. Crawford ${ }^{1}$, K. S. Manatt ${ }^{1}$, G. C. Toon ${ }^{1}$, K. W. Wong ${ }^{1}$, and \\ S. P. Sander ${ }^{1,2}$ \\ ${ }^{1}$ NASA Jet Propulsion Laboratory, California Institute of Technology, Pasadena, CA 91109, USA \\ ${ }^{2}$ UCLA Joint Institute for Regional Earth System Science and Engineering, University of California, Los Angeles, \\ CA 90095, USA
}

Correspondence to: D. Fu (dejian.fu@jpl.nasa.gov)

Received: 16 September 2013 - Published in Atmos. Meas. Tech. Discuss.: 7 October 2013

Revised: 14 January 2014 - Accepted: 22 January 2014 - Published: 6 March 2014

\begin{abstract}
The Los Angeles basin is a significant anthropogenic source of major greenhouse gases $\left(\mathrm{CO}_{2}\right.$ and $\left.\mathrm{CH}_{4}\right)$ and the pollutant $\mathrm{CO}$, contributing significantly to regional and global climate change. We present a novel approach for monitoring the spatial and temporal distributions of greenhouse gases in the Los Angeles basin using a high-resolution spectroscopic remote sensing technique. A new Fourier transform spectrometer called CLARS-FTS has been deployed since May, 2010, at Jet Propulsion Laboratory (JPL)'s California Laboratory for Atmospheric Remote Sensing (CLARS) on Mt. Wilson, California, for automated longterm measurements of greenhouse gases. The instrument design and performance of CLARS-FTS are presented. From its mountaintop location at an altitude of $1673 \mathrm{~m}$, the instrument points at a programmed sequence of ground target locations in the Los Angeles basin, recording spectra of reflected near-IR solar radiation. Column-averaged dry-air mole fractions of greenhouse gases (XGHG) including $\mathrm{XCO}_{2}, \mathrm{XCH}_{4}$, and $\mathrm{XCO}$ are retrieved several times per day for each target. Spectra from a local Spectralon ${ }^{\circledR}$ scattering plate are also recorded to determine background (free tropospheric) column abundances above the site. Comparisons between measurements from LA basin targets and the Spectralon ${ }^{\circledR}$ plate provide estimates of the boundary layer partial column abundances of the measured species. Algorithms are described for transforming the measured interferograms into spectra, and for deriving column abundances from the spectra along with estimates of the measurement precision and accuracy. The CLARS GHG measurements provide a means to infer relative, and possibly absolute, GHG emissions.
\end{abstract}

\section{Introduction}

The Los Angeles (LA) basin is a very large anthropogenic source of the important greenhouse gases $\mathrm{CO}_{2}$ and $\mathrm{CH}_{4}$, which contribute significantly to regional and global climate change (Hoornweg, 2010). Recent legislation in California, the California Global Warming Solutions Act (AB32), mandated a statewide cap for greenhouse gas emissions in 2020 at levels that prevailed in 1990 (Croes, 2012). Verifying the effectiveness of regional greenhouse gas (GHG) emission control requires high-precision, regional-scale measurement methods combined with models that capture the principal anthropogenic and biogenic sources and sinks. The existing California Air Resources Board (CARB) GHG measurement sites in the Los Angeles area are sparse, with far fewer sites than the CARB air quality network. Instruments in the network sample near the surface, where perturbations from local traffic sources, wind fields and planetary boundary layer (PBL) height changes can induce considerable variability in measured GHG concentrations on short time scales. McKain et al. (2012) used the coupled Weather Research and Forecasting-Stochastic Time-Inverted Lagrangian Transport (WRF-STILT) model to compare the sensitivity of surface and total column measurements of $\mathrm{CO}_{2}$ to changes in emissions within the Salt Lake City urban dome. Their simulations indicated that column measurements from the ground or space are more sensitive to emissions from the greater urban region than surface point measurements, and less sensitive to variability in PBL height. Thus, column measurements may allow for more precise estimation of anthropogenic emission 
trends in cities. Kort et al. (2012) analyzed space-based observations of the column-averaged dry-air mole fractions of $\mathrm{CO}_{2}$ from Greenhouse Gases Observing Satellite (GOSAT) over Los Angeles and Mumbai. Despite the relatively sparse spatial and temporal resolution and coverage provided by GOSAT, the column measurements showed statistically significant gradients between the cities and the surrounding areas, which could be used to detect emission changes of a few percent per year over a 5-10 yr observation period.

Despite the advantages inherent in the measurement of integrated column abundances, existing satellite and groundbased remote sensing instruments do not provide the temporal and spatial coverage required to quantify megacity GHG emissions. The repeat cycles and swaths of the orbital tracks of space-based instruments in low Earth orbits (e.g., GOSAT currently in orbit, Orbiting Carbon Observatory-2 (OCO-2) to be launched in July, 2014) do not provide daily monitoring of GHG emissions over megacities. There are also very few ground-based remote sensing instruments for column GHG measurements. The Total Carbon Column Observing Network (TCCON) is a collection of ground-based Fourier transform spectrometers (FTSs) recording direct solar spectra in the near-infrared (NIR) spectral region to measure the column-averaged volume mixing ratio (VMR) of GHGs. However, most TCCON stations are deployed at rural sites with small spatial gradients in order to provide calibration/validation data for satellite missions. Wunch et al. (2009) estimated the emission rates of GHGs over the LA basin using measurements from a TCCON station that was temporarily located in Pasadena, California. However, since TCCON stations employ direct solar viewing geometry, the spatial coverage of a single spectrometer is quite limited. This highlights the need for an approach that can produce daily GHG column abundance measurements over a wide spatial domain to complement other sensor networks in an urban airshed.

In this paper we describe a novel observing system that addresses the requirements for wide-area monitoring of GHGs to assess the impact of control measures on long-term megacity carbon emissions. The approach involves the use of a high-resolution Fourier transform infrared (FTIR) spectrometer on a mountaintop overlooking the Los Angeles basin to record atmospheric solar absorption spectra from a number of geographically distributed target points. The mountaintop viewing geometry offers two significant advantages relative to direct solar measurements from ground sites in the boundary layer: enhanced sensitivity to composition changes within the boundary layer due to the long low-altitude optical path lengths (tens of $\mathrm{km}$ ), and the capability to independently measure the composition within the free troposphere to provide background reference information. Apart from differences in viewing angles, the mountaintop vantage point also closely approximates the observations from geostationary orbit by space missions that will be launched later this decade (Key et al., 2012).
The paper is organized as follows: Sect. 2 describes the observing facility, California Laboratory for Atmospheric Remote Sensing (CLARS), and its instrumentation. Section 3 discusses the observational approach. Section 4 describes the data-processing algorithms, examples of retrievals, and error analysis. Section 5 outlines directions for future work. Conclusions are presented in Sect. 6.

\section{Observatory and instrumentation}

\subsection{CLARS observatory}

The California Laboratory for Atmospheric Remote Sensing (CLARS) is a NASA/Jet Propulsion Laboratory facility located on the grounds of Mount Wilson Observatory at $1673 \mathrm{~m}$ above sea level. The facility has a nearly unobstructed view of the entire Los Angeles basin. CLARS consists of an air-conditioned $23 \mathrm{~m}^{2}$ laboratory (Mobile Mini shipping container) fitted with an independent truss that penetrates the building roof for mounting of the pointing system. A telescope dome encloses the pointing system and truss. Instruments are mounted on optical tables inside the laboratory. An auxiliary building located near the laboratory houses in situ atmospheric monitoring instruments for continuous measurements of $\mathrm{CO}_{2}, \mathrm{CH}_{4}$, water vapor, $\mathrm{CO}, \mathrm{N}_{2} \mathrm{O}$ and black carbon.

The pointing system directs the external light sources into the FTS. A large $(43 \mathrm{~cm} \times 76 \mathrm{~cm})$ plano pointing mirror is mounted in an alt-azimuth gimbal with a pointing accuracy of $\pm 0.005^{\circ}$ and precision of $\pm 0.001^{\circ}$ in both axes, and a Cassegrain telescope $(41 \mathrm{~cm}$ aperture, $\mathrm{f} / 1.75)$ which can be inserted into the optical beam. In normal operation, the telescope is not employed. To improve vibration isolation, the legs of optical tables and pointing system truss are isolated from the laboratory building and mounted directly into the granite bedrock.

LabVIEW software controls the FTS instrument, pointing system, data handling and observatory housekeeping. Internet connections to the laboratory permit unattended operation of the instruments.

The CLARS facility also serves as a testbed for new remote sensing instruments. One such instrument is the Panchromatic Fourier Transform Spectrometer (PanFTS), a NASA Instrument Incubator Program (IIP)-funded development that addresses the measurement requirements of the NASA Geostationary Coastal and Air Pollution Events (GEO-CAPE) mission (National Research Council, 2007; Bekker et al., 2012; Fishman et al., 2012).

\subsection{CLARS-FTS}

A Fourier transform spectrometer was designed and built at Jet Propulsion Laboratory (JPL) for use in the measurements at CLARS. The CLARS-FTS is optimized for reflected sunlight measurements with high spectral resolution in the NIR 
region (4000-15000 $\left.\mathrm{cm}^{-1}\right)$. The following sections $(2.2 .1-$ 2.2.4) describe the optical design, optical alignment, signal chain, interferogram sampling methodology and performance of the CLARS-FTS instrument.

\subsubsection{Optical design}

Figure 1 shows optical layout diagrams of the FTS system for two operating configurations. In the atmospheric measurement mode, solar radiation is directed into the CLARSFTS instrument via a two-axis gimbaled line-of-sight pointing system and a gold-coated fold mirror with a diameter of $10 \mathrm{~cm}$ (top panel of Fig. 1). In the diagnostics mode, light from a quartz halogen lamp and collimator assembly (bottom panel of Fig. 1) illuminates the entrance aperture of the FTS. As described below, $\mathrm{HCl}$ gas cell spectra are recorded to check the instrument line shape function (ILS).

The core of the CLARS-FTS is a single-passed Michelsontype interferometer using cube-corner retro reflectors. This configuration is sensitive to shear misalignment, but insensitive to tip/tilt misalignments. The shear misalignment is compensated by the design and alignment of CLARS-FTS and verified by the characterization of ILS. A cube-corner mirror is mounted on a stage driven by a linear air bearing, which is used to vary the optical path difference (OPD) in the interferometer. The air-bearing stage has a built-in optical encoder with a resolution of $0.5 \mathrm{~nm}$ and provides accurate and repeatable position data. The air-bearing stage has no sliding surfaces in direct contact, so there are no lubricant or mechanical wear risks or "stiction". It provides mirror displacements up to $15 \mathrm{~cm}$. When using a single-sided interferogram configuration in a single-passed interferometer, it gives a maximum optical path difference (MOPD) of $30 \mathrm{~cm}$. The maximum spectral resolution is $0.02 \mathrm{~cm}^{-1}$, where spectral resolution is defined as 0.6/MOPD. The travel speed of the air-bearing slide is typically set to $0.3 \mathrm{~cm} \mathrm{~s}^{-1}$. Interferograms are acquired in both forward and backward scans of the moving mirror. The beam splitter and compensator substrates are calcium fluoride $\left(\mathrm{CaF}_{2}\right)$, with a silicon beam splitter coating optimized for the near-IR. The fixed and moving cube corners have a clear aperture of $6.3 \mathrm{~cm}$ and are coated with protected gold. The back-optics include a highquality gold-coated off-axis parabolic mirror (OAP, off-axis angle $=17^{\circ}$ ) with a diameter of $12.5 \mathrm{~cm}$, an adjustable circular field stop to define the interferometer field of view, and an inverse telescope (demagnification ratio 0.4 ) that consists of two $90^{\circ}$ gold-coated OAPs. The field stop diameter can be adjusted between 0.96 and $5.57 \mathrm{~mm}$ to achieve the full range of spectral resolution of CLARS-FTS. The metrology system consists of a frequency stabilized $( \pm 2 \mathrm{MHz})$ singlemode helium-neon laser co-aligned with the infrared (IR) beam, with the resulting fringes detected by a silicon photodiode. The interferogram sampling methodology is described in Sect. 2.2.3.

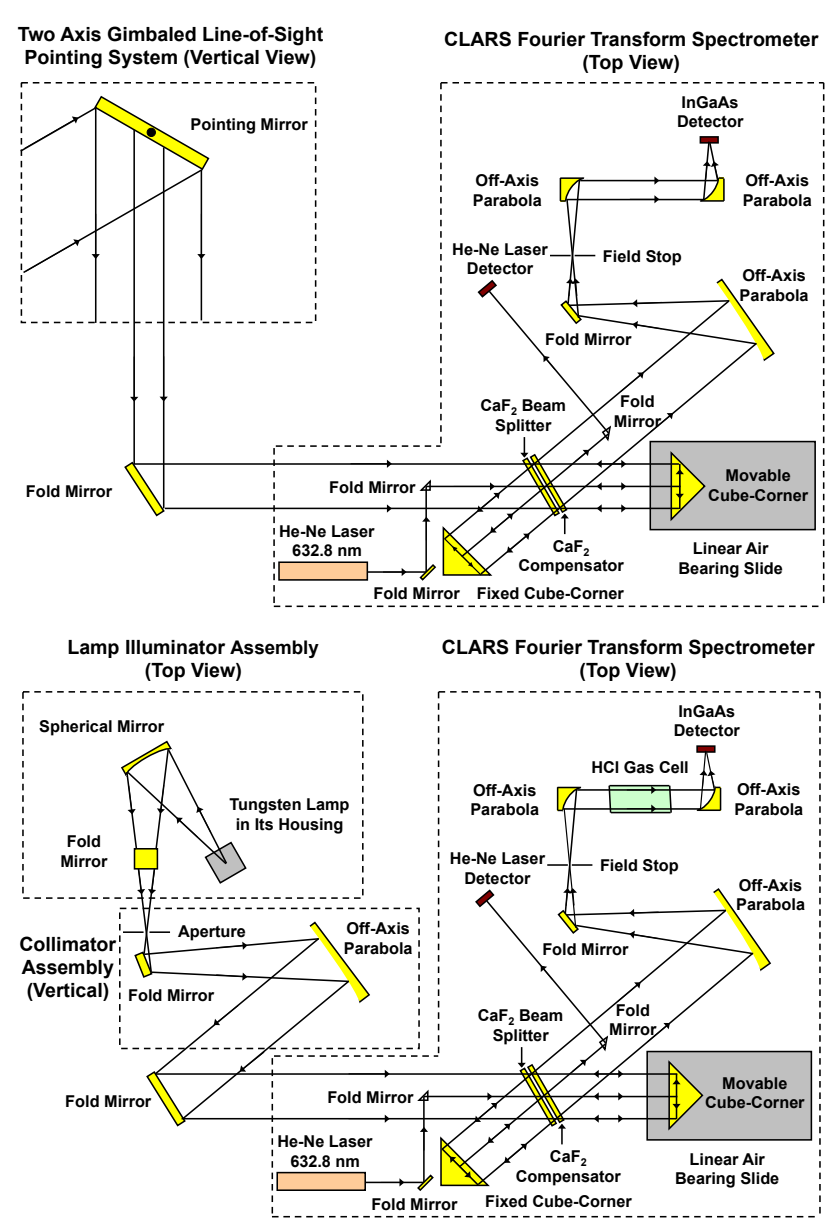

Fig. 1. Optical layouts of California Laboratory for Atmospheric Remote Sensing Fourier Transform Spectrometer (CLARS-FTS) for measuring greenhouse gases (top panel), and gas cell spectra to verify instrument alignment quality and stability (bottom panel). The core is a Michelson-type interferometer using cube-corner retro reflectors. It covers a spectral range of 4000 to $15000 \mathrm{~cm}^{-1}$ with a maximum optical path difference (MOPD) of $30 \mathrm{~cm}$ (or spectral resolution of $0.02 \mathrm{~cm}^{-1}$ ).

The high quality of alignment yields an instrument line shape function closely representing an ideal Fourier transform spectrometer. This is important because the ILS strongly influences the accuracy of the retrieved gas column abundance measurements. The CLARS-FTS optical axis is $17.78 \mathrm{~cm}$ above the optical bench surface. A He: Ne laser beam, which is not the metrology laser in CLARS-FTS, was set up to align the optical axis. The optical parts for the white light beam were mounted at the location centered at the optical axis. The fold mirrors used for directing the metrology laser beam were deployed along an axis which is parallel to the CLARS-FTS optical axis with $5 \mathrm{~cm}$ vertical distance. Two major steps are needed in the CLARS-FTS alignment: one is to align the two cube-corner mirrors in the interferometer for mitigating the lateral shifts (or shearing) while the moving cube-corner mirror is traveling on the air-bearing 
stage; the other is to align the field stop for co-aligning the instrument field of view (FOV) on the central Haidinger fringe at the field stop.

The fixed cube-corner mirror is mounted on an $x-y-z$ translation stage. To align the two cube-corner mirrors, the fold mirror of the metrology laser beam and the translation stage were adjusted alternately until the amplitude of the $\mathrm{He}: \mathrm{Ne}$ interferogram achieved a maximum that was independent of the optical path difference.

The field stop assembly is mounted on an $x-y-z$ translation stage. To locate the field stop in a plane perpendicular to the CLARS-FTS optical axis, a plane mirror was mounted on the field stop holder and adjusted for best autocollimation of the $\mathrm{He}: \mathrm{Ne}$ beam. The pointing system directed sunlight reflected from a known LA basin landmark into the FTS. The translation stage was aligned in the $z$ (focus) axis to achieve the best focus of the landmark image on the field stop. The field stop was then adjusted in the $x-y$ plane perpendicular to the optical axis to center the $\mathrm{He}$ : Ne beam on the field stop. To verify the proper alignment of the cube corners and field stop, interferograms were recorded using a $1.2 \mu \mathrm{m}$ singlefrequency external cavity diode laser which scattered off a diffuser plate at the entrance aperture of the FTS. Finally, using a broad-band quartz-halogen light source coupled to a collimator, spectra were recorded using an $\mathrm{HCl}$ gas cell. As discussed in Sect. 2.2.4, these spectra were inverted to provide information on the instrument line shape function.

\subsubsection{Signal chain}

Two channels are employed in the interferometer signal chain: one for the IR detector and the other for the reference laser detector. The IR channel consists of a wavelength range extended Indium Gallium Arsenide (InGaAs) photodiode detector, a variable gain transimpedance pre-amplifier, a 24-bit sigma-delta analog-to-digital converter (ADC) and a PC data acquisition computer running under LabVIEW. The InGaAs detector is thermoelectrically cooled to $190 \mathrm{~K}$ with an active area of $3.14 \mathrm{~mm}^{2}$ and spectral range from 0.7 to $2.5 \mu \mathrm{m}$. The laser metrology channel consists of a variable gain silicon photoreceiver coupled to a second channel of the ADC. The two ADC channels are sampled simultaneously.

\subsubsection{Interferogram sampling methodology}

CLARS-FTS uses the method of uniform time sampling (UTS) in which the IR and reference laser interferograms are recorded in equal time increments (Brasunas and Cushman, 1997; Manning and Combs, 1999; Campbell, 2008) then resampled into equal optical path difference increments in a post-processing step. The post-processing algorithm detects variations of the mirror velocity using the laser interferogram, computes actual optical path difference for each data point that was recorded with a constant time interval, and resamples the white light interferograms from the time domain to the path difference domain (Brault, 1996; Griesmann et al., 1999; Pougatchev et al., 2000). The UTS method has a number of advantages over the conventional sampling scheme that uses zero-crossings of the laser interferogram to trigger the digitization of the IR interferogram: (1) digitization at a constant sampling frequency permits the use of delta-sigma ADCs with very high-resolution digitizers (24-bit), which are well suited to the high dynamic range requirements for digitization of IR interferograms; (2) oversampling and digital filtering by the delta-sigma ADC eliminate compensation required for differential group delay between the IR and laser signal channels; and (3) oversampling extends the optical frequency range into the visible and near-UV spectral regions. The post-processing algorithm, which converts CLARS-FTS interferograms to spectra, is described in Sect. 4.1.

\subsubsection{Characterization of the CLARS-FTS instrument line shape}

To accurately derive the mixing ratios of atmospheric trace gases from measured spectra, it is necessary to take into account the ILS function of the spectrometer, defined as the instrument's output response to a purely monochromatic input (Davis et al., 2001; Griffiths and De Haseth, 2007). For an ideal Fourier transform spectrometer, the theoretical ILS in the frequency domain (Eq. 1) is a sinc function convolved with a rectangular function (Connes, 1961):

$\operatorname{ILS}(v)=\operatorname{SINC}(v, \Delta x) \otimes \operatorname{RECT}\left(v, v_{0}, \theta\right)$,

where $\quad \operatorname{SINC}(\nu, \Delta x) \equiv \frac{\sin (2 \pi v \Delta x)}{2 \pi v \Delta x} ; \quad \operatorname{RECT}\left(\nu, v_{0}, \theta\right) \equiv$ $\left\{\begin{array}{cc}1 & \text { if }-0.5 \nu_{0} \theta^{2} \leq v \leq 0 \\ 0 & \text { otherwise }\end{array}\right\} ; \Delta x$ is the optical path difference; $v$ and $v_{0}$ (in $\mathrm{cm}^{-1}$ ) are two adjacent frequencies to be distinguished; and $\theta$ is the angular radius of the circular internal FOV. The sinc function accounts for the finite optical path difference of an FTS, while the rectangular function accounts for the field stop size.

To characterize the ILS, the FTS was configured using the external lamp. The experimental setup is shown in the bottom panel of Fig. 1. A gas cell containing $\mathrm{HCl}$ vapor (length $=9.96 \mathrm{~cm}$; pressure $=5.107 \mathrm{hPa}$; temperature $=300 \mathrm{~K}$; calcium fluoride $\left(\mathrm{CaF}_{2}\right)$ wedged windows $)$ was inserted into the collimated beam path before the detector. When conducting daily atmospheric measurements, the gas cell was removed from the collimated beam to avoid signal attenuation. The absorption spectra of the $\mathrm{HCl}$ gas cell were recorded using CLARS-FTS $\left(\Delta x=27.2 \mathrm{~cm} ; v_{0}=\right.$ $5765 \mathrm{~cm}^{-1} ; \theta=2.632 \mathrm{mrad}$; with a circular field stop of $1.6 \mathrm{~mm}$ in diameter). The LINEFIT program (Hase et al., 1999) was applied to simulate $\mathrm{HCl}$ absorption spectra (top panel of Fig. 2) and retrieve the ILS (bottom plot of Fig. 2) from the observed spectral line shape. As shown in Fig. 2, the residuals in the spectral domain are essentially random. The root mean square (RMS) of the spectral fitting residuals is 
about $0.08 \%$ of the transmitted radiance and matches the estimated spectral signal-to-noise ratio (SNR) $(1300: 1)$ of the gas cell spectra for $10 \mathrm{~min}$ of integration. Equation (1) was applied to compute the theoretical ILS using the CLARSFTS parameters. The bottom panel of Fig. 2 presents the measured (black curve) and theoretical (blue curve) ILS functions. The agreement indicates that the instrument was well aligned when these measurements were taken. Additional diagnostics include imaging of the Haidinger fringes at the field stop when the FTS is illuminated by scattered light from a beam-expanded $\mathrm{He}$ : $\mathrm{Ne}$ laser, and recordings of the ILS from a near-IR external cavity (single frequency) diode laser. Diagnostics such as these are performed seasonally to verify the alignment quality and stability.

\subsection{Pointing calibration}

Accurate pointing knowledge of the instrument field of view is necessary for proper geolocation of the retrieved slant column abundances, and setup of the radiative transfer (RT) model used to fit the observed spectra. The intrinsic accuracy and repeatability of the pointing mirror gimbal are on the order of a hundredth of the CLARS-FTS instrument FOV. However, additional pointing errors arise from gimbal tilt and minor position-dependent flexing of the pointing system structure. A calibration procedure was devised to relate the readings of the pointing system encoders to the geolocated centroid of the instrument FOV.

Initially, a tracking camera, permanently mounted on the pointing system truss, was co-boresighted with the FTS optical axis. This was accomplished by temporarily replacing the InGaAs detector on the FTS with a second camera, which viewed the same image as the detector. The tracking camera was then aligned to view the same scene as the focal plane camera. The pointing system was directed toward sixteen targets across the LA basin with known latitude, longitude and altitude. The azimuth $\left(\theta_{C, i}\right)$ and elevation $\left(\psi_{C, i}\right)$ angles viewed from the CLARS site toward the sixteen targets $(i=1-16)$ were computed using

$$
\begin{aligned}
& \theta_{C, i}= \\
& \quad \arctan \left(\frac{\sin \left(\lambda_{C}-\lambda_{T, i}\right) \cos \left(\phi_{C}-\phi_{T, i}\right)}{\cos \left(\phi_{C}\right) \sin \left(\phi_{T, i}\right)-\sin \left(\phi_{C}\right) \cos \left(\phi_{T, i}\right) \cos \left(\lambda_{C}-\lambda_{T, i}\right)}\right),
\end{aligned}
$$

$\psi_{C, i}=\pi-\arctan \left(\frac{D_{i}}{Z_{C}-Z_{T, i}}\right)$,

where $\lambda_{C}$ and $\lambda_{T, i}$ are the longitudes of the CLARS site and target $i, \phi_{C}$ and $\phi_{T, i}$ are the latitudes of the CLARS site and target $i, Z_{C}$ and $Z_{T, i}$ are the altitude of the CLARS site and target $i$, and $D_{i}$ is the great circle distance between CLARS site and target $i . D_{i}$ can be computed from

$$
\begin{aligned}
D_{i} & =R_{\mathrm{E}} \arccos \left(\sin \left(\phi_{C}\right) \sin \left(\phi_{T, i}\right)\right. \\
& \left.+\cos \left(\phi_{C}\right) \cos \left(\phi_{T, i}\right) \cos \left(\lambda_{C}-\lambda_{T, i}\right)\right),
\end{aligned}
$$
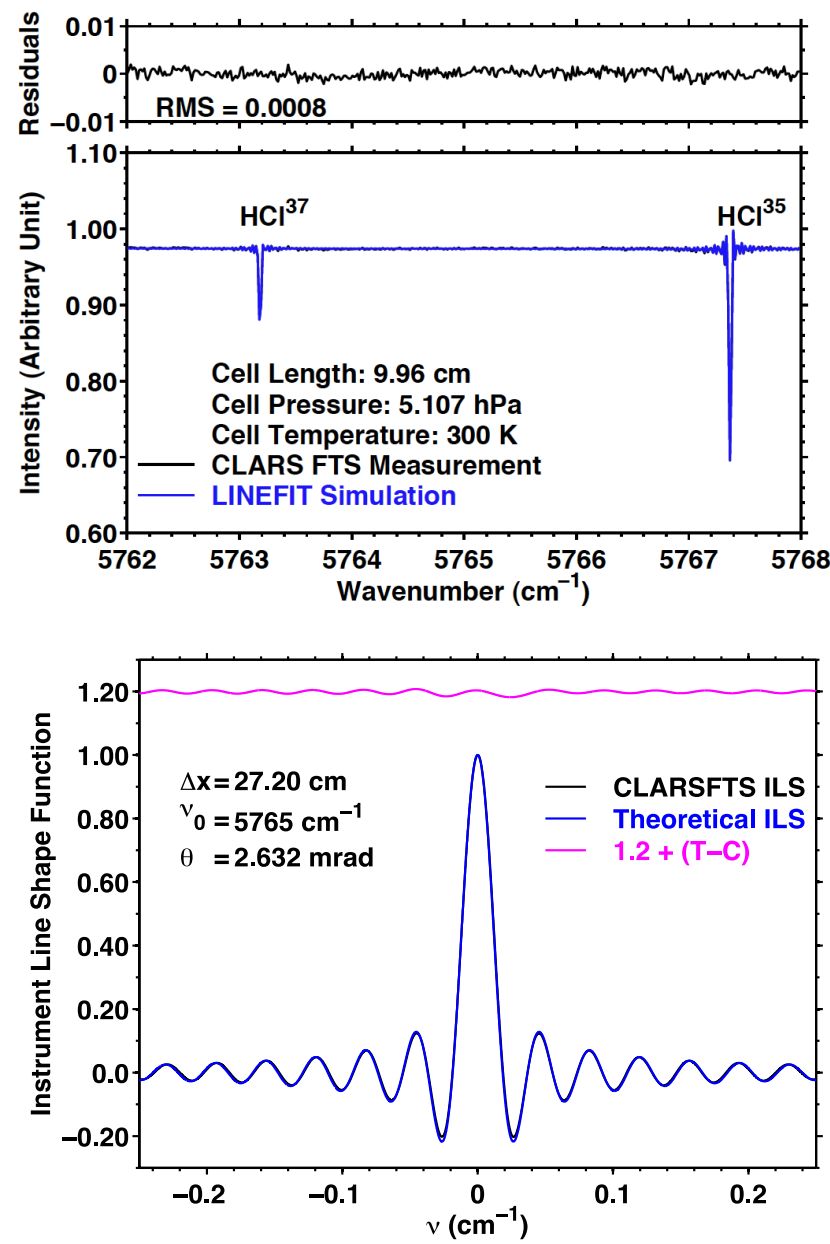

Fig. 2. Top panel: $\mathrm{HCl}$ gas cell spectra near $5765 \mathrm{~cm}^{-1}$ measured by CLARS-FTS (black curve) and simulated by LINEFIT program (blue curve). Bottom panel: instrument line shape functions (ILS) of CLARS-FTS (black line) and an ideal FTS (blue line); the differences between theoretical ILS and CLARS-FTS ILS (magenta line; offset by 1.2 for clarity). The spectral fitting residuals (top panel) were normalized by the continuum level of measured $\mathrm{HCl}$ cell spectra. The root mean square of spectral fitting residual was $0.08 \%$ of spectral continuum level. The following parameters were used in both measurements and simulation: optical path difference $=27.2 \mathrm{~cm}$; angular radius of the circular internal field of view $=2.632 \mathrm{mrad} ; \mathrm{HCl}$ cell length $=9.96 \mathrm{~cm}$; gas cell total pressure $=5.107 \mathrm{hPa} ; \mathrm{HCl}$ gas pressure in the cell $=5.107 \mathrm{hPa}$; cell temperature $=300 \mathrm{~K}$. The symmetric ILS indicated the high quality of CLARS-FTS alignment. The full width half maximum (FWHM) of CLARS-FTS ILS is $0.022 \mathrm{~cm}^{-1}$.

where $R_{\mathrm{E}}$ is the radius of Earth. Equations (2) to (4) assume that Earth is spherical.

The azimuth $\left(\theta_{E, i}\right)$ and elevation $\left(\psi_{E, i}\right)$ angles of the gimbal's azimuth-elevation encoder for each target position, $i$, were fitted to the following equations to obtain the coefficients $A_{i}$ :

$\theta_{E, i}=A_{1}-A_{2} \theta_{C, i}$, 
$\psi_{E, i}=A_{3}-0.5\left\{\psi_{C, i}-\left[A_{4}+A_{5} \sin \left(A_{6} \theta_{C, i}+A_{7}\right)\right]\right\}$,

where $\phi_{C, i}$ and $\psi_{C, i}$ were computed using Eqs. (2) and (3); $A_{i=1-7}$ are calibration coefficients determined from a leastsquares fit to the 16 calibration targets. Using the above equations, the latitude, longitude, and elevation of any target can be used to drive the azimuth and elevation of the gimbal within its mechanical limits. After applying the pointing calibration the total uncertainty of the CLARS-FTS pointing system is $0.17^{\circ}(1 \sigma)$ in azimuth (about $30 \%$ of CLARS-FTS FOV, yielding a ground distance of $\sim 60 \mathrm{~m}$ for a target that is $20 \mathrm{~km}$ away from CLARS) and $0.045^{\circ}(1 \sigma)$ in elevation $(8 \%$ of CLARS-FTS FOV, yielding a ground distance of $\sim 16 \mathrm{~m}$ for a target that is $20 \mathrm{~km}$ away from CLARS).

\subsection{Weather station}

Meteorological data are recorded at the CLARS facility. Prior to 18 December 2012, a Davis Vantage weather station was employed. It provided measurements of barometric pressure (digital accuracy $\pm 1.0 \mathrm{hPa}$ ), air temperature $\left( \pm 0.5^{\circ} \mathrm{C}\right)$, relative humidity $( \pm 5 \%)$, wind speed $( \pm 5 \%)$, wind direction $\left( \pm 5^{\circ}\right)$, and precipitation $( \pm 4 \%)$. After this date, an R.M. Young weather system was employed to replace the Davis Vantage system, which was destroyed by lightning. Sensors are mounted $\sim 5 \mathrm{~m}$ above the CLARS container measuring barometric pressure (accuracy $\pm 0.3 \mathrm{hPa}$ from $-40^{\circ} \mathrm{C}$ to $\left.60^{\circ} \mathrm{C}\right)$, air temperature $\left( \pm 0.3^{\circ} \mathrm{C}\right.$ from $-50{ }^{\circ} \mathrm{C}$ to $\left.50^{\circ} \mathrm{C}\right)$, relative humidity $\left( \pm 1 \%\right.$ at $\left.23^{\circ} \mathrm{C}\right)$, solar radiation ( $\pm 5 \%$ under daylight spectrum conditions), wind speed $\left( \pm 0.5 \mathrm{~m} \mathrm{~s}^{-1}\right)$, wind direction $\left( \pm 5^{\circ}\right)$, and the precipitation rate ( $2 \%$ up to $25 \mathrm{~mm} \mathrm{~h}^{-1}, 3 \%$ up to $50 \mathrm{~mm} \mathrm{~h}^{-1}$ ). Real-time weather data are available online at http://clarsweather.jpl. nasa.gov/. The archived data are available on the Weather Underground web site (2014).

\section{Measurements using CLARS-FTS}

Three operating modes are on the CLARS-FTS measurement schedule: Los Angeles Basin Surveys (LABS), Spectralon ${ }^{\circledR}$ Viewing Observations (SVO), and Instrument Status Evaluation Measurements (ISEM). The upper panel of Supplement Fig. S1 shows the viewing geometry of LABS and SVO. LABS and SVO are the observations that CLARS-FTS conducts daily. In LABS mode, the pointing system stares at each ground site in the Los Angeles basin and CLARS-FTS records atmospheric absorption spectra over a broad spectral range (4000-8600 $\mathrm{cm}^{-1}$ ) using reflected sunlight as the light source. SVO provide the background level of GHG gases. In SVO, CLARS-FTS measures the greenhouse gas concentration above the CLARS site by pointing at a Spectralon ${ }^{\circledR}$ target on the rooftop. Since the CLARS mountaintop site is located above the boundary layer, SVO measurements give the background trace gas abundances in the free troposphere. Pointing at the Spectralon ${ }^{\circledR}$ plate instead of the Sun simplifies pointing system requirements by eliminating the need to track the Sun. This mode has the additional advantages of attenuating the direct solar beam intensity to levels comparable to the reflected radiance from the land targets, and also provides spectra averaged over the entire solar disk. The Spectralon ${ }^{\circledR}$ plate is a nearly Lambertian scattering surface over the spectral range of $4000-25000 \mathrm{~cm}^{-1}$ with a reflectance greater than $98.5 \%$ over the range of $6700-$ $25000 \mathrm{~cm}^{-1}$ and $95 \%$ over the range $4000-40000 \mathrm{~cm}^{-1}$. ISEM, which is conducted monthly, uses $\mathrm{HCl}$ gas cell measurements and IR laser measurements for verifying the alignment quality and stability. The approach was discussed in Sect. 2.2.4.

Daily measurements from CLARS-FTS follow a preprogrammed sequence, in which the CLARS pointing system either directs light reflected from the targets in the Los Angeles basin (LABS mode) or the Spectralon ${ }^{\circledR}$ plate on the rooftop of the CLARS site (SVO mode) into the spectrometer. The sequences can be changed to accommodate the needs of special observations. Target site selection was guided by imagery from the NIR camera to ensure a uniform surface albedo across the spectrometer FOV. Supplement Table S1 lists the target coordinates, measurement mode, and descriptions of targets in a typical measurement sequence. Supplement Fig. S1 shows the location of targets over the LA basin. The measurement sequence is repeated $\sim 5-8$ times daily.

A spectral resolution of $0.12 \mathrm{~cm}^{-1}$ is used in daily CLARS-FTS measurements. The typical interferometer scan time to obtain an absorption spectrum is $18 \mathrm{~s}$ for the maximum OPD setting of $5 \mathrm{~cm}$ (spectral resolution $0.6 / \mathrm{MOPD}=0.12 \mathrm{~cm}^{-1}$, an angular radius of the circular internal field of view $=4.970 \mathrm{mrad}$, with a circular field stop of $3.03 \mathrm{~mm}$ in diameter) and OPD speed of $0.6 \mathrm{~cm} \mathrm{~s}^{-1}$ (corresponding to a mirror velocity of $0.3 \mathrm{~cm} \mathrm{~s}^{-1}$ ). In the measurement sequence, CLARS-FTS averages 12 single scan spectra $(\sim 3 \mathrm{~min}$ measurement time $)$ for each target site to achieve a spectral SNR of $\sim 300: 1$ after coaddition. Figure 3 presents sample atmospheric absorption spectra measured using CLARS-FTS on 3 September 2012 around 10:33 a.m. local time (solar zenith angle $32.442^{\circ}$ ). The measurement was taken by targeting Santa Anita Park $\left(34.141^{\circ} \mathrm{N}, 118.042^{\circ} \mathrm{W}, 155 \mathrm{~m}\right.$ a.s.1., $9.3 \mathrm{~km}$ slant distance to the CLARS site), Arcadia, California.

In the downward viewing geometry used in the CLARSFTS measurements, the sunlight travels through the boundary layer twice: once on the way to the target and a second time from the target to CLARS. The resulting light path through the boundary layer is typically greater than $20 \mathrm{~km}$ which is several times longer than other commonly used viewing geometries, e.g., observing the direct solar beam from the surface, or measurement of surface-reflected sunlight from aircraft and spacecraft. 

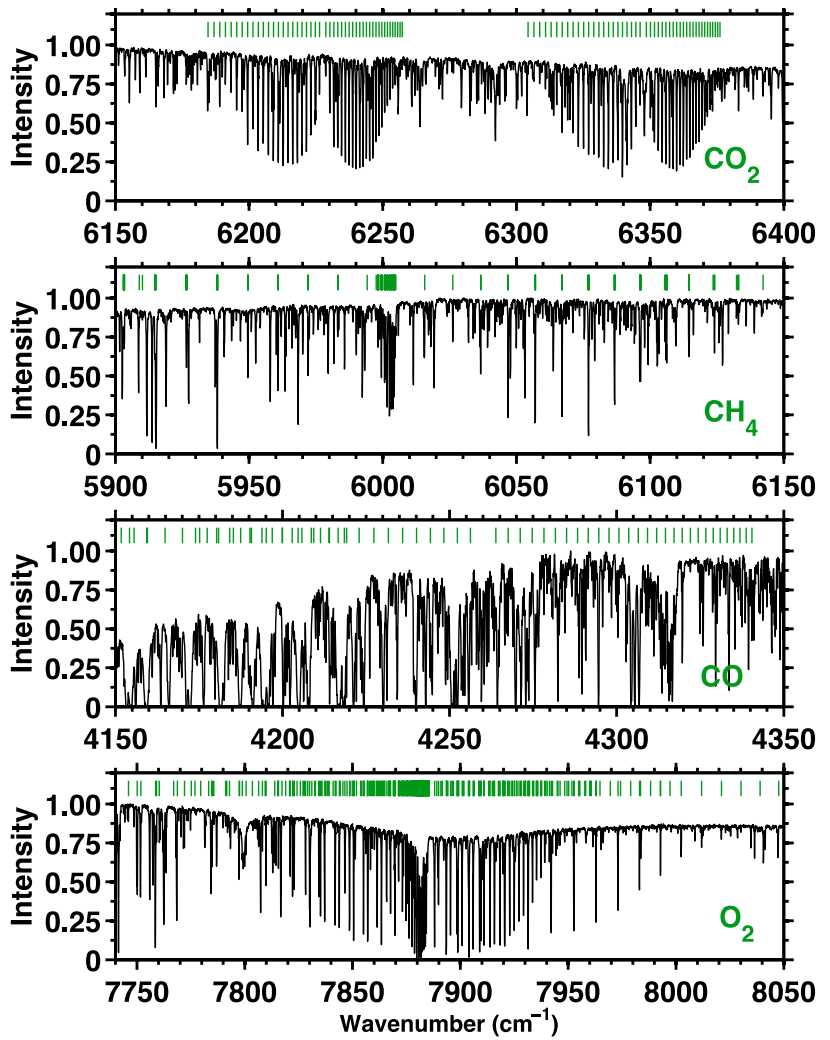

Fig. 3. Atmospheric absorption spectra measured using CLARSFTS with a spectral resolution of $0.12 \mathrm{~cm}^{-1}$ on 3 September 2012 . The measurement was taken by targeting at the land surface of Santa Anita Park $\left(34.141^{\circ} \mathrm{N}, 118.042^{\circ} \mathrm{W}, 155 \mathrm{~m}\right.$ above sea level, $9.3 \mathrm{~km}$ slant distance to the CLARS site), Arcadia, California. The green vertical bars indicate the spectral line positions of target gases of interests. The spectra were co-added using 12 single scan spectra centered at 10:33 local time (solar zenith angle $32.442^{\circ}$ ) with total measurement time about $3 \mathrm{~min}$. The spectral signal-to-noise ratio (SNR) is $420: 1$.

\section{Data processing and error analysis}

This section describes the algorithms for conversion of interferograms to spectra (Sect. 4.1), spectra to slant column densities of trace gases along the light path (Sect. 4.2), computation of column average volume mixing ratios (Sect. 4.3) and sample retrievals for two reflection points in the LA basin (Sect. 4.4). In Sect. 4.5, the estimation of measurement uncertainties is presented.

\subsection{Interferogram to spectrum}

As discussed in Sect. 2.2.3, CLARS-FTS records singlesided interferograms with uniform-time sampling in both the IR and reference channels. The CLARS interferogram processing program (CLARS-IPP) converts interferograms (Level 1a data) into spectra (Level $1 \mathrm{~b}$ data). The CLARS-IPP algorithm applies the following post-processing steps to each recorded scan: (1) converting time-domain interferogram to path-difference domain interferogram; (2) correcting for solar intensity variations (SIV); (3) correcting phase error; and (4) converting the interferogram into a spectrum using the fast Fourier transform (FFT) algorithm.

Conversion of the interferogram from the time domain to the path difference domain requires an accurate estimate of the instantaneous mirror velocity. This information is obtained from the reference laser interferograms. In CLARSIPP, the algorithm that computes the instantaneous velocity was written for the Mars Atmosphere Trace Molecule Occultation Spectrometer (MATMOS) project (Pingree et al., 2007; Bekker et al., 2008, 2009). This technique has been demonstrated in previous studies (Brasunas and Cushman, 1997; Manning and Combs, 1999; Campbell, 2008). In the original method of Brault (1996), the laser interferogram zero crossings are detected by a hardware comparator, with the intervals measured by counting pulses from a highfrequency clock triggered by the comparator. These values are used to resample the IR interferogram at constant intervals of OPD. The method used by CLARS-FTS is to simultaneously digitize the laser and IR interferograms and perform the laser phase extraction and resampling steps in the CLARS-IPP algorithm.

SIV corrections are performed using the method developed by Keppel-Aleks et al. (2007). This approach involves correcting the interferogram DC component for source brightness fluctuations by dividing by a low-pass filtered version of the interferogram recorded with DC coupling. Following this correction, the interferogram is phasecorrected using the Forman method (Forman et al., 1966) and processed into a spectrum using a complex-to-real FFT (Bergland, 1969).

A pre-screening step removes individual spectra of low quality, e.g., scenes likely contaminated by clouds. The cloud scene pre-screening of single-scan CLARS-FTS measurement is performed by comparing the intensities of spectral radiances between adjacent scans to identify outliers. Singlescan spectra are then co-added over a period of $3 \mathrm{~min}(12$ single-scan spectra), to increase the signal-to-noise ratio (for LABS $>=300: 1$; for SVO $>=450: 1$ ). Depending on the season, the total number of co-added spectra within a single day ranges from 160 to 260 , repeating the number of LABS measurement sequences from 5 to 8 times.

\subsection{Spectrum to slant column densities (SCD) of trace gases}

To derive slant column abundances of atmospheric trace gases from the measured absorption spectra, we use a modified version of the GFIT program. GFIT is derived from the Occultation Display Spectra (ODS) program (Norton and Rinsland, 1991), which was created for the analysis of Atmospheric Trace Molecule Spectroscopy Mission (ATMOS), and incorporates many improvements. The GFIT program 
is the standard spectral analysis tool of the TCCON network (Wunch et al., 2009, 2010, 2011) and is also used for analysis of MkIV balloon spectra (Sen et al., 1999) and ATMOS spectra (Irion et al., 2002). Since the viewing geometry of CLARS-FTS measurements differs from the direct Sunviewing geometry used by TCCON, several modifications are needed. These modifications were applied to the GFIT February 2013 version. The modified GFIT program consists of a RT model coupled to a model of the solar spectrum to calculate the monochromatic spectrum of light that originates from the Sun, passes through the atmosphere, reflects from the Earth's surface, makes a second pass through the lower atmosphere and enters the CLARS-FTS instrument. The radiances are then processed through the CLARS-FTS instrument model to simulate the measured radiances at the appropriate spectral resolution.

GFIT uses the Voigt line shape function and optionally includes line mixing for $\mathrm{CO}_{2}, \mathrm{CH}_{4}$ and $\mathrm{O}_{2}$. Atmospheric absorption coefficients are calculated line by line for each gas in a chosen spectral window, and are used together with the assumed temperature, pressure, and VMR profiles in the forward model to calculate the atmospheric transmittance spectrum. The Voigt profile is used in the analysis of CLARSFTS spectra. The simulated spectra were compared with measured spectra, and the a priori VMR profiles are iteratively scaled to minimize the RMS differences between the calculated and measured spectra. The theoretical ILS, verified by fits to low-pressure $\mathrm{HCl}$ gas cell lines, is used in calculating the forward model. The atmosphere is represented by 70 levels in the forward model calculation. Pressure- and temperature-dependent absorption coefficients are computed for each absorption line at each level. Profiles of temperature and geopotential height are obtained from the NOAA Climate Diagnostics Center (CDC), with 17 pressure levels from 1000 to $10 \mathrm{hPa}$ and $1^{\circ} \times 1^{\circ}$ geographic resolution. At pressures less than $10 \mathrm{hPa}$, climatological profiles of temperature and geopotential height are used. Measured surface pressures at the LA basin weather stations are used to define the lowest model level.

The monochromatic atmospheric absorption spectrum is then multiplied by a synthetic solar spectrum $(I)$ which is represented by the following equation:

$$
I_{i, j}=\mathbf{S}_{j} e^{-\mathbf{X}_{i, j}^{2}} / \sqrt{\mathbf{D}_{j}^{4}+\mathbf{X}_{i, j}^{2} \mathbf{Y}_{j}^{2}},
$$

where $i$ is the index of the monochromatic wavelength grid; $j$ is the index of the empirical solar spectral lines; and $\mathbf{S}_{j}$ $, \mathbf{X}_{i, j}, \mathbf{Y}_{j}$, and $\mathbf{D}_{j}$ are the line center optical thickness (dimensionless), the frequency difference from line center $\left(\mathrm{cm}^{-1}\right)$, 1/e-folding width $\left(\mathrm{cm}^{-1}\right)$ and Doppler width $\left(\mathrm{cm}^{-1}\right)$ in the empirical solar line list, respectively. The solar line list covers the range from 550 to $15000 \mathrm{~cm}^{-1}$ and was derived from FTS solar spectra using ATMOS and MkIV balloon spectra for the range $550-5650 \mathrm{~cm}^{-1}$ (Geller, 1992, 1995), and Kitt Peak ground-based spectra for $5000-15000 \mathrm{~cm}^{-1}$
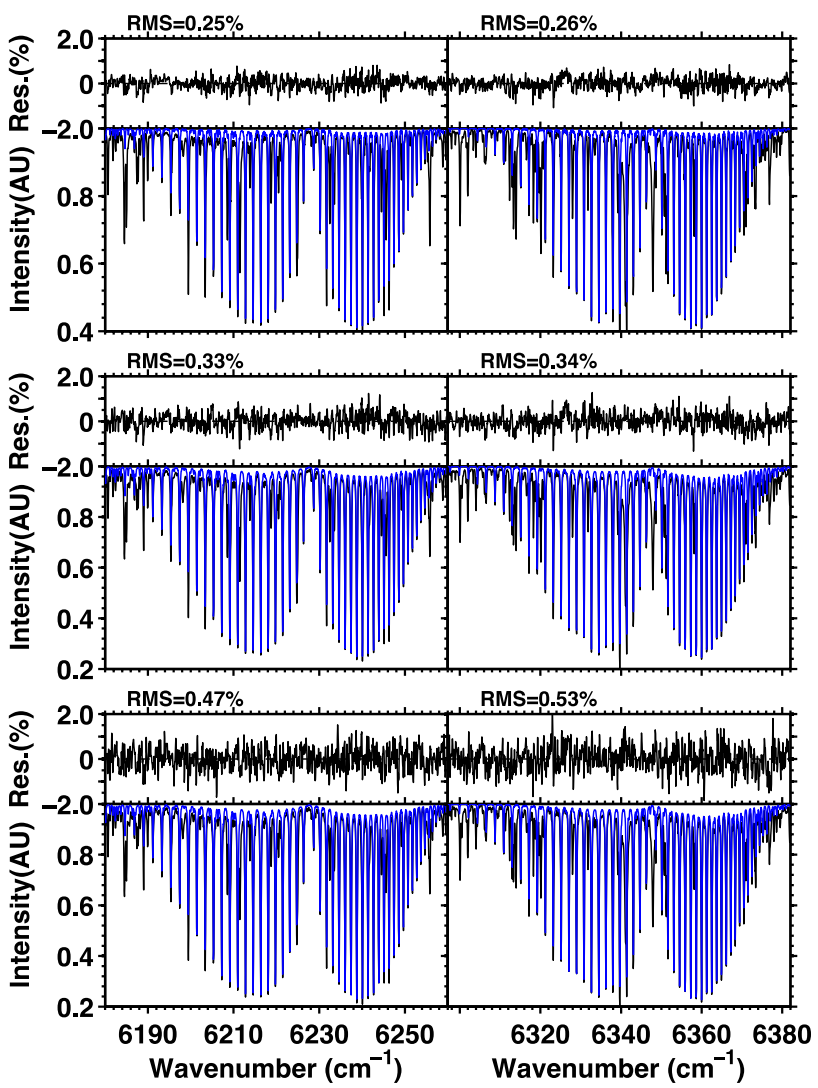

Fig. 4. Sample spectral fittings of $\mathrm{CO}_{2}$ bands near $1.6 \mu \mathrm{m}$ region using the CLARS-FTS measurements in the Spectralon ${ }^{\circledR}$ viewing (top panels); pointing at Santa Anita Park, Arcadia (middle panels); or pointing at west Pasadena (bottom panels). The measurements were taken on 3 January 2013 with a solar zenith angle (SZA) of $58.62^{\circ}$ (top panels), $58.39^{\circ}$ (middle panels), and $57.89^{\circ}$ (bottom panels). Each spectrum is from 12 co-added scans, which were taken consecutively over $3 \mathrm{~min}$. The spectral SNRs are 532:1, 417:1, and 227 : 1 from top to bottom panels, respectively. The measured radiances subtracting the simulated spectra, which included contributions of all trace gases and solar lines, yield the spectral fitting residuals. In all panels, black curves are measured spectra and blue curves are the estimated contribution of $\mathrm{CO}_{2}$ absorption to the spectral fittings. Contributions of other species in these spectral regions are not shown.

(Livingston and Wallace, 1991; Wallace et al., 1993). The solar model includes both disk center and disk-integrated line lists. Both have been used in the analysis of ground-based (TCCON), balloon-borne (MkIV), and satellite-borne FTS spectra (e.g., GOSAT, O'Dell et al., 2012).

We retrieve $\mathrm{CO}_{2}, \mathrm{CH}_{4}, \mathrm{CO}$, and $\mathrm{O}_{2}$ using the spectral bands and the sources of spectroscopic parameters that are listed in Table 1, similar to those used by TCCON. The uncertainties of measured XGHG from the errors in spectroscopic parameters and other sources are estimated in Sect. 4.5.2. For $\mathrm{O}_{2}$, the a priori VMR profile is constant with altitude (a dry-air VMR of 0.2095). For $\mathrm{CO}_{2}, \mathrm{CH}_{4}$ and $\mathrm{CO}$, 
Table 1. Spectral range, species that have spectral signatures within the spectral range, and sources of spectroscopic parameters used in spectral fittings.

\begin{tabular}{|c|c|c|}
\hline $\begin{array}{l}\text { Spectral range } \\
\mathrm{cm}^{-1}\end{array}$ & (source of spectroscopic line parameters*) Gases included in spectral fits & $\begin{array}{l}\text { Auxiliary } \\
\text { parameters to fit }\end{array}$ \\
\hline $6180.0-6260.0$ & ${ }^{1} \mathrm{CO}_{2},{ }^{2} \mathrm{H}_{2} \mathrm{O},{ }^{2} \mathrm{HDO},{ }^{3,4} \mathrm{CH}_{4}$ & $\mathrm{cl}^{\mathrm{a}} \mathrm{ct}^{\mathrm{b}} \mathrm{fs}^{\mathrm{c}}$ \\
\hline $6297.0-6382.0$ & ${ }^{1} \mathrm{CO}_{2},{ }^{2} \mathrm{H}_{2} \mathrm{O},{ }^{2} \mathrm{HDO}$ & $\mathrm{cl} \mathrm{ct} \mathrm{fs}$ \\
\hline $4810.0-4890.0$ & ${ }^{1} \mathrm{CO}_{2},{ }^{5} \mathrm{~N}_{2} \mathrm{O},{ }^{2} \mathrm{H}_{2} \mathrm{O},{ }^{2} \mathrm{HDO},{ }^{6} \mathrm{CH}_{4},{ }^{7} \mathrm{CO}$ & $\mathrm{cl} \mathrm{ct} \mathrm{fs}$ \\
\hline $5880.0-5996.0$ & ${ }^{3,4} \mathrm{CH}_{4},{ }^{1} \mathrm{CO}_{2},{ }^{2} \mathrm{H}_{2} \mathrm{O},{ }^{2} \mathrm{HDO}$ & $\mathrm{DLPBF}^{\mathrm{d}}$ \\
\hline $6007.0-6145.0$ & ${ }^{3,4} \mathrm{CH}_{4},{ }^{1} \mathrm{CO}_{2},{ }^{2} \mathrm{H}_{2} \mathrm{O},{ }^{2} \mathrm{HDO}$ & DLPBF \\
\hline $4208.7-4257.3$ & ${ }^{7} \mathrm{CO},{ }^{6} \mathrm{CH}_{4},{ }^{2} \mathrm{H}_{2} \mathrm{O},{ }^{2} \mathrm{HDO}$ & $\mathrm{clct}$ fs \\
\hline $4262.0-4318.8$ & ${ }^{7} \mathrm{CO},{ }^{6} \mathrm{CH}_{4},{ }^{2} \mathrm{H}_{2} \mathrm{O},{ }^{2} \mathrm{HDO}$ & DLPBF \\
\hline $7765.0-8005.0$ & ${ }^{8} \mathrm{O}_{2},{ }^{9} \mathrm{O}_{2}$ CIA,${ }^{2} \mathrm{H}_{2} \mathrm{O}$ & $\mathrm{cl}$ ct fs \\
\hline
\end{tabular}

${ }^{a}$ Continuum level; ${ }^{b}$ continuum tilt; ${ }^{c}$ frequency shift and ${ }^{\mathrm{d}}$ fitting the continuum level using discrete Legendre polynomial basis functions (DLPBF).

* All of the spectroscopic parameters are available in HITRAN 2008 compilation prepared by Rothman et al. (2009).

1 Toth et al. (2008); ${ }^{2}$ Toth (2005) with the addition (in 2005-2007) of hundreds of weak $\mathrm{H}_{2} \mathrm{O}$ lines that are visible in humid, high-airmass TCCON spectra. Jenouvrier et al. (2007) subsequently identified many of these weak lines; ${ }^{3}$ GFIT (February 2013 version) includes the weak $\mathrm{CH}_{4}$ lines extending from 6180 to $6220 \mathrm{~cm}^{-1}$ which were provided by Linda Brown; ${ }^{4}$ Frankenberg et al. (2008); ${ }^{5}$ Toth $(1999,2000) ;{ }^{6}$ Brown et al. (2003); ${ }^{7}$ Brault et al. (2003); ${ }^{8}$ line list created by Andrew Orr-Ewing using the PGOPHER code, based on lab measurements of Newman et al. (1999). The widths were subsequently modified to be $1.5 \%$ larger than those in Yang et al. (2005) in order to minimize the airmass dependence of retrieved $\mathrm{O}_{2}$ column density, as described by Washenfelder et al. (2006). $\mathrm{O}_{2}$ quadrupoles lines are from Gordon et al. (2010) and ${ }^{9}$ the collision-induced absorption (CIA) is represented by a pseudo-line list based on fits to lab spectra described by Smith and Newnham (2000). The CIA is not used in the determination of the $\mathrm{O}_{2}$ column. It is fitted only to minimize its impact on the discrete $\mathrm{O}_{2}$ lines.

the assumed a priori VMR profiles vary seasonally in agreement with model output from Olsen and Randerson (2004). The sensitivity of the column GHG retrievals to different reasonable a priori functions is expected to be within $1 \%$ based on the previous study of Washenfelder et al. (2006).

In order to characterize the precision of CLARS-FTS measurements (described in Sect. 4.5.1), special observations were conducted which cycled between the Spectralon ${ }^{\circledR}$ target and two nearby reflection points in the LA basin, Santa Anita Park (a horse racing track in the city of Arcadia) and west Pasadena. These targets are labeled \#0,\#17 and \#27, respectively, in Table 1 and Fig. S1 of the Supplement. Figure 4 shows typical spectral fits of $\mathrm{CO}_{2}$ bands near $1.6 \mu \mathrm{m}$ using the CLARS-FTS measurements pointing at Spectralon ${ }^{\circledR}$ (top panels), Santa Anita Park (middle panels) and west Pasadena (bottom panels). The spectral fits were made using two $\mathrm{CO}_{2}$ bands (blue lines) centered at $6220 \mathrm{~cm}^{-1}$ (noted as MW6220 thereafter) and $6339 \mathrm{~cm}^{-1}$ (noted as MW6339 thereafter) separately. The RMS of the spectral fitting residuals in both $\mathrm{CO}_{2}$ bands is reasonably close to the expected values since the chi-squared tests of spectral fitting residuals yielded values generally within 1.3 (Fig. 5). The RMS of spectral fitting residuals shows a dependency on the spectral SNR (Fig. 5). Figure 6 shows the averaged spectral fitting residuals within MW6220 and MW6339 using the measurements over three targets on 3 January 2013. The co-addition of fitting residuals reduces the random spectral noise contribution and preserves the systematic fitting residuals. The systematic fitting residuals were observed in the measurements from all LA basin targets as well as the Spectralon ${ }^{\circledR}$ target. The majority of the "spikes" in the left panels of Fig. 6 arise from imperfect line parameters of disk-integrated solar lines and $\mathrm{H}_{2} \mathrm{O}$ lines (Supplement Figs. S2 and S3), although some of the systematic residuals arise from errors in the spectroscopic parameters of $\mathrm{CO}_{2}$ and neglect of line mixing. In addition, uncertainties in atmospheric temperature, pressure and humidity profiles arising from the limited spatial/temporal resolution of National Center for Environmental Prediction (NCEP) data contribute to systematic residuals, especially for water vapor lines. Overall, the magnitude of the systematic residuals is smaller than $0.5 \%$ of the spectral continuum levels, with peak values most often appearing at the wavelength of nontarget species such as $\mathrm{H}_{2} \mathrm{O}$. The imperfect spectroscopic parameters and line shape function affect the accuracy of retrieved GHG column amounts since they can bias the retrieved GHG column abundances. Most of this bias can be corrected by calibration against secondary measurements. Wunch et al. (2010) discussed a calibration procedure for TCCON measurements, which use the same spectroscopic parameters as this work, that reduced the systematic bias for $\mathrm{CO}_{2}$ from 1.1 to $0.2 \%$ and $\mathrm{CH}_{4}$ from 2.2 to $0.4 \%$.

\subsection{Column average volume mixing ratio of GHG in dry air (XGHG)}

XGHG can be calculated from the retrieved GHG column, according to

$\mathrm{XGHG}=\frac{\mathrm{GHG} \text { column }}{\text { dry air total column }}$ 

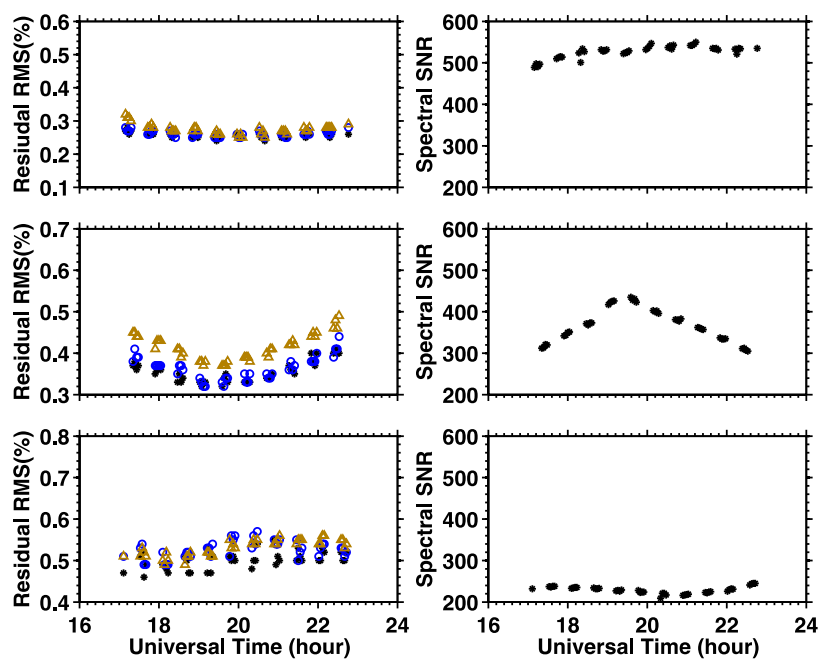

Fig. 5. Root mean square (RMS) of spectral fitting residuals (left panels) and spectral SNR (right panels) as a function of time for the measurements of $\mathrm{CO}_{2}$ and $\mathrm{O}_{2}$ column densities in Spectralon ${ }^{\circledR}$ viewing (top panels); over Santa Anita Park (middle panels); over west Pasadena (bottom panels). Three spectral bands centered at $6220 \mathrm{~cm}^{-1}$ (black stars, noted as MW6220 thereafter), $6339 \mathrm{~cm}^{-1}$ (blue circles, noted as MW6339 thereafter) and $7885 \mathrm{~cm}^{-1}$ (gold triangles, noted as MW7885 thereafter) are presented. The spectral SNRs were nearly identical over the three spectral bands in a measured spectrum, but they vary among spectra. The measurements were performed on 3 January 2013. The spectral fitting residuals were normalized by the spectral continuum levels prior to the computation of RMS values. The spectral fitting residuals were dominated by the photon shot noise. The chi-squared tests of spectral fitting residuals yielded values less than 1.3.

where

dry air total column $=\frac{\mathrm{O}_{2} \text { column }}{0.2095}$.

Using Eq. (8) to compute the column average GHG VMR will improve the measurement precision of atmospheric GHG concentrations (Washenfelder et al., 2006; Fu et al., 2008 ) if systematic errors in the column abundances are common to both the GHG and $\mathrm{O}_{2}$. These could arise from errors in the spectra, such as instrumental line shape, detector nonlinearity, or from errors in the calculated slant path due to uncertainty in the surface pressure, solar zenith angle (SZA), pointing or aerosol scattering. Errors due to nonideal ILS are expected to be small because proper FTS alignment was verified by several methods as discussed in Sect. 2.2.4. Detector nonlinearity may be significant when viewing very bright sources such as the Sun; this effect is negligible for reflected sunlight measurements such as those employed by CLARS-FTS. However, errors in the calculated slant path (due to errors in surface pressure, SZA or neglect of aerosol scattering), water vapor (for determination of dry-air column mixing ratios), spectral zero level offsets and solar intensity variations due to thin clouds will cause uncertainties in the
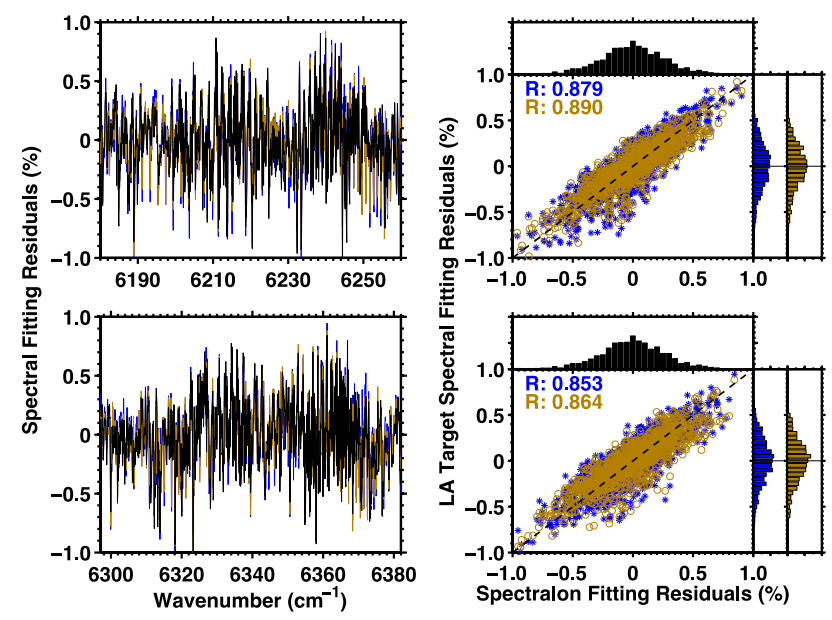

Fig. 6. The spectral fitting residuals (left panels) and their correlation, Pearson's correlation coefficients $(R)$, and histograms (right panels) with MW6220 (top panels) and MW6339 (bottom panels) for $\mathrm{CO}_{2}$ slant column density measurements. In left panels, black curve is for Spectralon ${ }^{\circledR}$ viewing; blue curve is for west Pasadena; gold curve is for Santa Anita Park. In right panels, blue stars are the correlation between Spectralon ${ }^{\circledR}$ and west Pasadena; gold circles are the correlation between Spectralon ${ }^{\circledR}$ and Santa Anita Park; the black dash lines indicate the one-to-one correlation. The spectral fitting residuals were generated using the co-addition of residuals of 41 spectral fittings of Spectralon ${ }^{\circledR}$ target, 41 spectral fittings of west Pasadena target, and 40 spectral fits of Santa Anita Park target on 3 January 2013. The systematic residuals arise from the imperfect line shape function and spectroscopic parameters in addition to uncertainties of atmospheric pressure and temperature parameters since the magnitude and positions of spikes in the fitting residuals consistently appear in all three target scenes. However, the magnitude of most systematic fitting residuals is within $0.5 \%$ of spectral continuum levels.

retrieved column densities of target gases and $\mathrm{O}_{2}$. Most of these errors are mitigated in the measurement approach and retrieval algorithms (Eq. 8). The effect of aerosol scattering on individual retrievals is assessed by comparing the measured $\mathrm{O}_{2}$ column abundance with the value derived from the surface pressure at the target. Differences exceeding a threshold value trigger the setting of a data quality flag which is used in subsequent data filtering steps. The remaining impacts are estimated in Sect. 4.5.

\subsection{Sample retrievals from CLARS-FTS}

As an illustration of the data from the CLARS-FTS, sample results from several days of measurements are presented in this section; more detailed analyses of the data will be presented in subsequent papers. Figure 7 shows the $\mathrm{XCO}_{2}$ and the differences of $\mathrm{XCO}_{2}$ between MW6220 and MW6339 as a function of time using the CLARS-FTS measurement over three targets on 3 January 2013. The difference in $\mathrm{XCO}_{2}$ between MW6220 and MW6339 using the Spectralon ${ }^{\circledR}$ target 

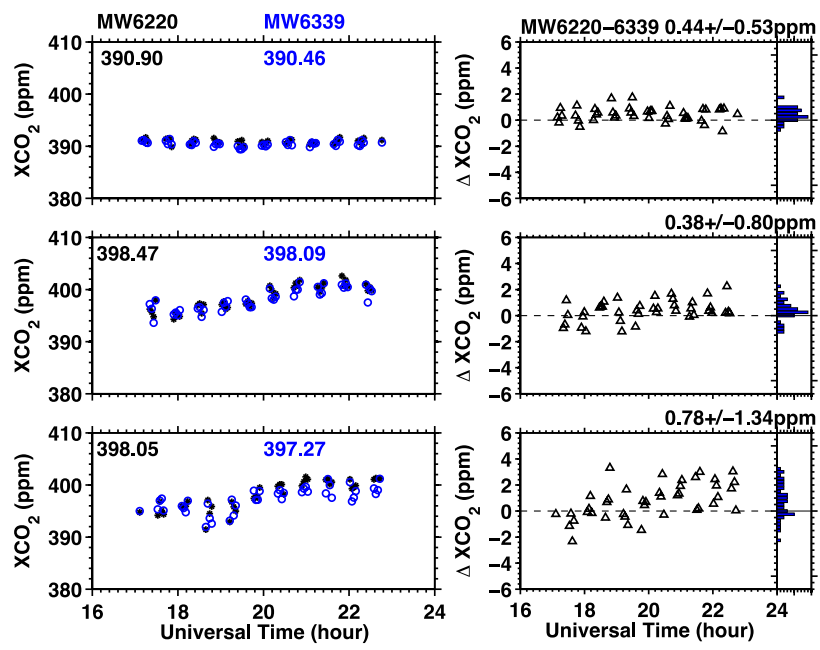

Fig. 7. $\mathrm{XCO}_{2}$ (in parts per million, ppm) measured by CLARSFTS with MW6220 (black dots) and MW6339 (blue circles) on 3 January 2013 (left panels) and differences of retrieved $\mathrm{XCO}_{2}$ between the two spectral regions and the histograms (right panels) in the Spectralon ${ }^{\circledR}$ viewing (SV, top panels), towards Santa Anita Park (SAP, middle panels), and towards west Pasadena (WP, bottom panels). Black stars in left panels: $\mathrm{XCO}_{2}$ obtained using the spectral region of MW6220. Compared to the background levels of $\mathrm{XCO}_{2}$ (top panels), $\mathrm{XCO}_{2}$ over SAP (middle panels) and WP (bottom panels) show higher values (mean SAP-SV: $7.60 \mathrm{ppm}$; mean WP-SV: $6.98 \mathrm{ppm}$ ) and present stronger diurnal cycles than those measurements over CLARS site. The $\mathrm{XCO}_{2}$ values retrieved from MW6220 are higher than those of MW6339. The mean differences between MW6220 and MW6339 are 0.44, 0.38 and 0.78 ppm for $\mathrm{SV}, \mathrm{SAP}$ and WP, respectively. This difference also appeared in the spectral analyses of the TCCON measurements $(\sim 0.15 \mathrm{ppm})$. For both CLARS-FTS and TCCON, HITRAN 2008 line parameters result in improved $\mathrm{XCO}_{2}$ band-to-band consistency compared to HITRAN 2004.The systematic differences in retrieved $\mathrm{XCO}_{2}$ values between the two bands are due to both spectroscopic line parameters and interfering species.

(41 measurements) is $0.44 \pm 0.53 \mathrm{ppm}(1 \sigma)$. For the measurements over Santa Anita Park and west Pasadena, the $\mathrm{XCO}_{2}$ values using MW6220 are also higher than those of MW6339. A difference between the two microwindow retrievals is a consistent feature of the data. Another example is shown for 18 January 2013 (Supplement Fig. S4), for which the spectral SNR and RMS of the spectral fitting residuals (Supplement Fig. S5) are similar to 3 January 2013 (Figs. 4 and 5). The microwindow difference also appears consistently in TCCON measurements $(\sim 0.15 \mathrm{ppm})$. Both CLARS-FTS and TCCON results, which are based on the HITRAN 2008 line list, show improvements in the band-toband consistency of $\mathrm{XCO}_{2}$ compared to those which use the HITRAN 2004 line list. For example, as shown in Fig. 6 of Washenfelder et al. (2006), $\mathrm{XCO}_{2}$ using MW6220 is about $0.9 \mathrm{ppm}$ higher than MW6339. These systematic differences of retrieved $\mathrm{XCO}_{2}$ values between two spectral bands likely arise from systematic errors in spectroscopic parameters between the two bands and the number and intensity of spectral features from interfering species.

As discussed above, SVO measurements are representative of the unpolluted free troposphere, while LABS measurements carry the spatial and temporal signatures of boundary layer emissions. Figure 7 and Supplement Fig. S4 illustrate the differences in $\mathrm{XCO}_{2}$ obtained using the $\mathrm{SVO}$ and LABS measurement modes. Figure 7 shows that the $\mathrm{XCO}_{2}$ values for Santa Anita Park (middle panels) and west Pasadena (bottom panels) on 3 January 2013 average 7.60 and 6.98 ppm higher, respectively, than for Spectralon ${ }^{\circledR}$. These two targets also show much larger diurnal variability. Similar enhancements and diurnal variability of $\mathrm{XCO}_{2}$ were also observed on other days, e.g., the measurements on 18 January 2013 (Supplement Fig. S4).

Two spectral regions, which are centered at $5938 \mathrm{~cm}^{-1}$ (noted as MW5938 thereafter) and $6076 \mathrm{~cm}^{-1}$ (noted as MW6076 thereafter), were utilized in measuring $\mathrm{CH}_{4}$ column abundances. Figure 8 presents sample spectral fits of $\mathrm{CH}_{4}$ measurements. The overall spectral fitting of $\mathrm{CH}_{4}$ shows qualities similar to that of $\mathrm{CO}_{2}$ bands in terms of the RMS of spectral fitting residuals (Fig. 9) and the magnitude of systematic fitting residuals (Fig. 10, Supplement Figs. S6 and S7). $\mathrm{XCH}_{4}$ using the MW6076 is generally higher than that of using MW5938. $\mathrm{XCH}_{4}$ over Santa Anita Park and west Pasadena show enhanced values compared to the Spectralon ${ }^{\circledR}$ levels (Fig. 11). Similar enhancements and diurnal variability of $\mathrm{XCH}_{4}$ were observed on other days, e.g., the measurements on 18 January 2013 (Supplement Fig. S8). The spectral fitting qualities of $\mathrm{CH}_{4}$ bands are identical between two days (Fig. 9, Supplement Fig. S9) due to the similar meteorological conditions.

The observations of XCO utilized the measured spectral region near $2.36 \mu \mathrm{m}$. The enhancement and stronger diurnal variability of XCO were seen in measurements over both Santa Anita Park and west Pasadena targets, compared to the Spectralon ${ }^{\circledR}$ values. Measurement of XCO presents an extra challenge due to the weakness of the CO spectral features, the low solar radiance in this region and the overlap with interfering spectral lines from $\mathrm{CH}_{4}$ and water vapor. The broad and strong absorption features of interfering species in the $\mathrm{CO}$ spectral region led to the spectral fitting residuals for the $\mathrm{CO}$ bands being about a factor of two higher than those near $1.6 \mu \mathrm{m}$ (Supplement Fig. S10). Weak CO absorption features result in lower sensitivities near the surface compared to the measurements of $\mathrm{CO}_{2}, \mathrm{CH}_{4}$, and $\mathrm{O}_{2}$. Despite these problems, as shown in Fig. 12 and Supplement Fig. S11, the XCO measurements provide reliable data for both LA basin targets and Spectralon ${ }^{\circledR}$. 


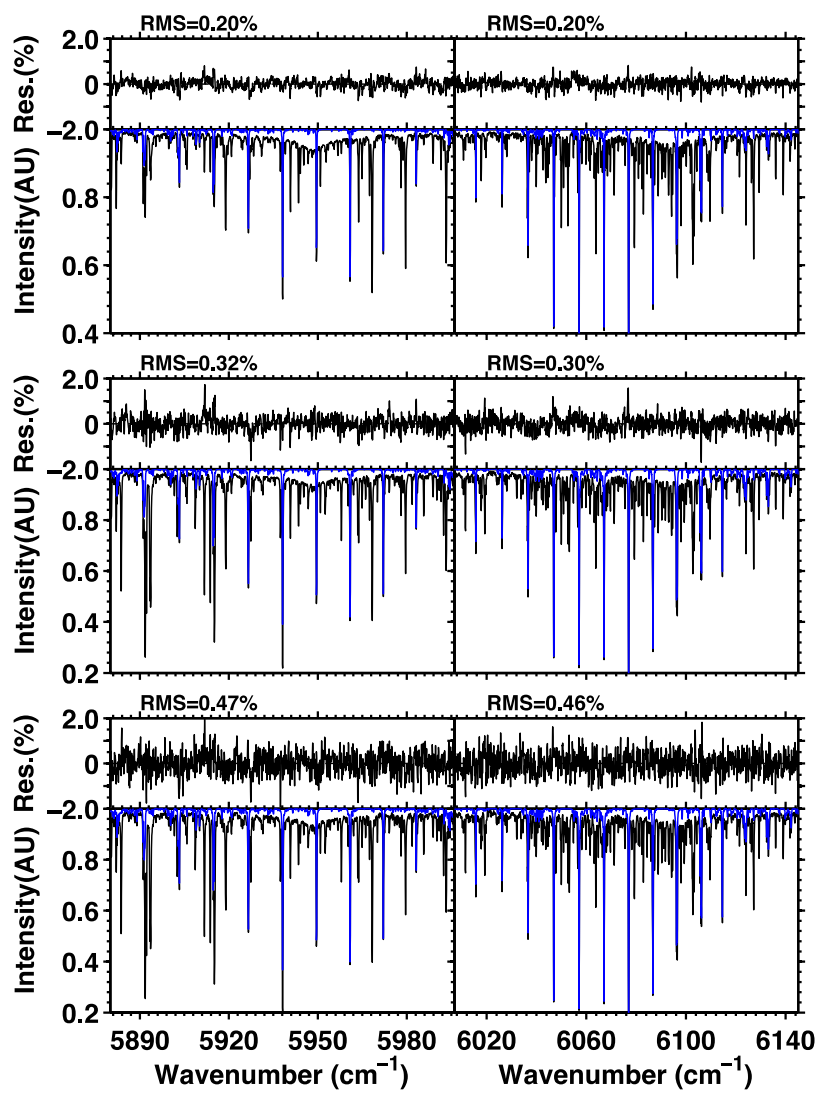

Fig. 8. Sample spectral fittings of $\mathrm{CH}_{4}$ bands, which are centered at $5938 \mathrm{~cm}^{-1}$ (noted as MW5938 thereafter) and $6076 \mathrm{~cm}^{-1}$ (noted as MW6076 thereafter) using the CLARS-FTS measurements in the Spectralon ${ }^{\circledR}$ viewing (top panels); pointing at Santa Anita Park (middle panels); or pointing at west Pasadena (bottom panels). The measurements were taken on 3 January 2013 with a solar zenith angle (SZA) of $58.62^{\circ}$ (top panels), $58.39^{\circ}$ (middle panels), and $57.89^{\circ}$ (bottom panels). Each spectrum is from 12 co-added scans, which were taken consecutively over $3 \mathrm{~min}$. The spectral SNRs are $532: 1,417: 1$, and $227: 1$ from top to bottom panels, respectively. The measured radiances subtracting the simulated spectra, which included contributions of all trace gases and solar lines, yield the spectral fitting residuals. In all panels, black curves are measured spectra and blue curves are the estimated contribution of $\mathrm{CH}_{4}$ absorption to the spectral fittings. Contributions of other species in these spectral regions are not shown.

The sensitivities of CLARS-FTS measurements are characterized by their column-averaging kernels. Figure 13 shows the column-averaging kernels for $\mathrm{CO}_{2}, \mathrm{CH}_{4}, \mathrm{CO}$, and $\mathrm{O}_{2}$ for the Spectralon ${ }^{\circledR}$ (top panels) and Santa Anita Park (bottom panels) targets.

\subsection{Measurement uncertainty of XGHG}

The uncertainties in retrieved values of column-averaged VMR for both LA basin and Spectralon ${ }^{\circledR}$ measurements contain random and systematic components. The random
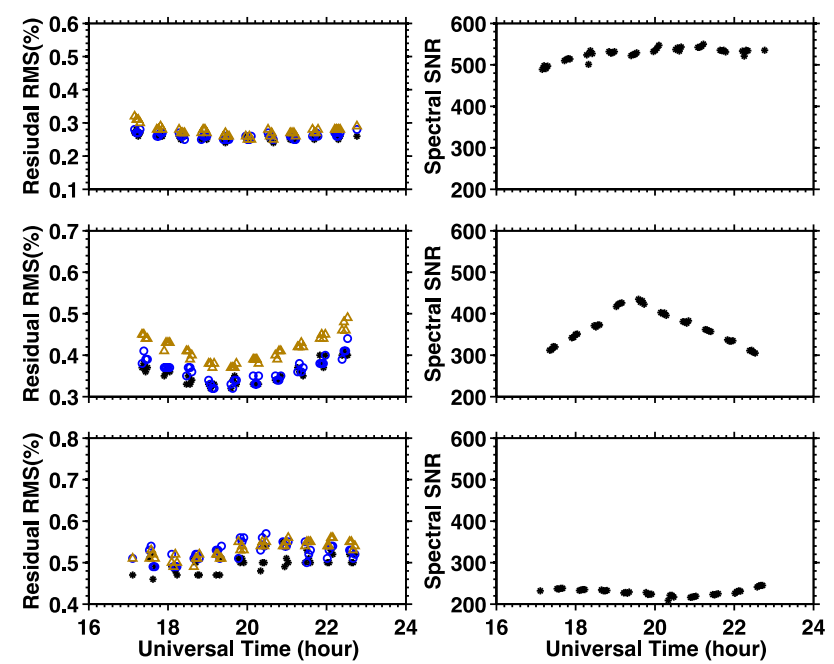

Fig. 9. Root mean square (RMS) of spectral fitting residuals (left panels) and spectral SNR (right panels) as a function of time for the measurements of $\mathrm{CH}_{4}$ and $\mathrm{O}_{2}$ column densities in Spectralon ${ }^{\circledR}$ viewing (top panels), over the Santa Anita Park (middle panels), and over west Pasadena (bottom panels). Three spectral bands centered at $5938 \mathrm{~cm}^{-1}$ (black stars, noted as MW5938 thereafter), $6076 \mathrm{~cm}^{-1}$ (blue circles, noted as MW6076 thereafter) and $7885 \mathrm{~cm}^{-1}$ (gold triangles, noted as MW7885 thereafter) are presented. The spectral SNRs were nearly identical over the three spectral bands in a measured spectrum, but vary among spectra. The measurements were performed on 3 January 2013. The spectral fitting residuals were normalized by the spectral continuum levels prior to the computation of RMS values. The spectral fitting residuals were dominated by the photon shot noise. The chi-squared tests of spectral fitting residuals yielded values generally within 1.3.

component (Sect. 4.5.1) determines the measurement precision for XGHG retrievals. The systematic component (Sect. 4.5.2) controls the overall measurement accuracy.

\subsubsection{Estimation of XGHG measurement precision}

The uncertainties returned by GFIT assume a Gaussian distribution of residuals from the spectral fits. In reality, this is usually not the case due to systematic artifacts (e.g., errors/omissions in the spectroscopic database, the modeling of the instrument response, and uncertainty in the pointing accuracy resulting in errors in the computed optical path). These can dominate the spectral fitting residuals produced by GFIT. Since these artifacts are generally the same from spectrum to spectrum, an uncertainty calculated from the RMS spectral fit generally underestimates the true precision. Hence, we utilize the differences of XGHG between two spectral regions to estimate the precisions of CLARS-FTS measurements. These differences include a systematic bias coming from variations in the spectral signatures of interfering species, and the inconsistencies between spectroscopic parameters within these spectral regions. The remaining variation ( $1 \sigma$ standard deviation of the mean differences) is given 
Table 2. Estimated measurement precisions ${ }^{\mathrm{a}}$.

\begin{tabular}{llllll}
\hline & \multicolumn{2}{c}{ 3 January 2012} & & \multicolumn{2}{c}{18 January 2012} \\
\cline { 2 - 3 } \cline { 5 - 6 } $\mathrm{XCO}_{2}$ & $0.37,0.57,0.95 \mathrm{ppm}^{\mathrm{b}}$ & $0.09,0.14,0.24 \% \mathrm{c}$ & & $0.31,0.66,0.76 \mathrm{ppm}^{\mathrm{b}}$ & $0.08,0.17,0.19 \%^{\mathrm{c}}$ \\
$\mathrm{XCH}_{4}$ & $2.31,4.56,8.46 \mathrm{ppb}$ & $0.13,0.25,0.46 \%$ & & $2.77,4.90,9.11 \mathrm{ppb}$ & $0.15,0.26,0.49 \%$ \\
$\mathrm{XCO}$ & $2.08,6.16,12.31 \mathrm{ppb}$ & $2.00,4.01,8.01 \%$ & & $1.85,5.51,10.65 \mathrm{ppb}$ & $1.88,4.19,8.06 \%$ \\
\hline
\end{tabular}

a The method of measurement precision estimation is introduced in Sect. 4.5.1. ${ }^{\mathrm{b}}$ Data in the left column are the estimated measurement precisions of XGHG over Spectralon ${ }^{\circledR}$, Santa Anita Park and west Pasadena targets, respectively. Unit is in parts per million (ppm) for $\mathrm{XCO}_{2}$ and in parts per billion (ppb) for $\mathrm{XCH}_{4}$ and $\mathrm{XCO} .{ }^{c}$ Data in the right column are the percentage measurement precisions, which were estimated with respect to the mean XGHG over Spectralon ${ }^{\circledR}$, Santa Anita Park and west Pasadena targets, respectively.
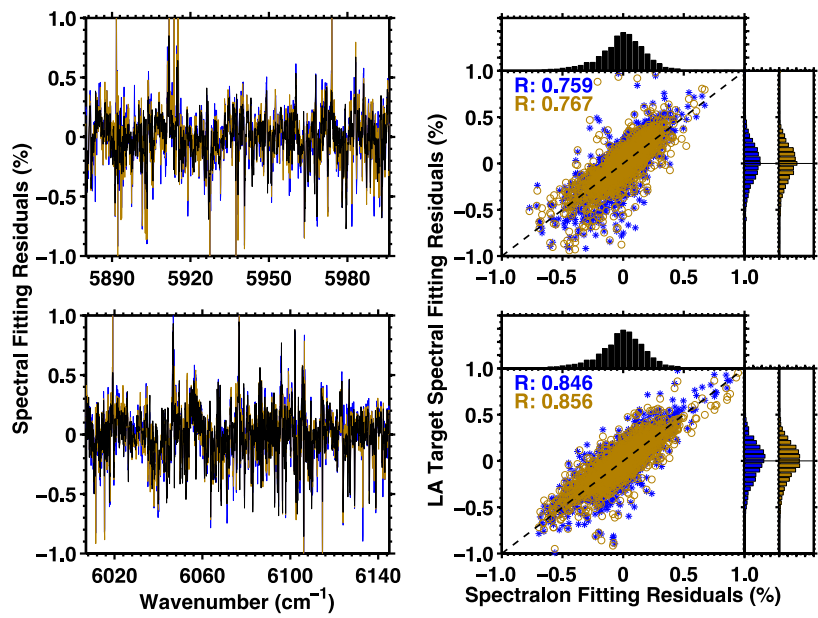

Fig. 10. The spectral fitting residuals (left panels) and their correlation, Pearson's correlation coefficients $(R)$, and histograms (right panels) with MW5938 (top panels) and MW6076 (bottom panels) for $\mathrm{CH}_{4}$ slant column density measurements. In left panels, black curve is for Spectralon ${ }^{\circledR}$ viewing; blue curve is for west Pasadena; gold curve is for the Santa Anita Park. In right panels, blue stars are the correlation between Spectralon ${ }^{\circledR}$ and west Pasadena; gold circles are the correlation between Spectralon ${ }^{\circledR}$ and Santa Anita Park; the black dash lines indicate the one-to-one correlation. The spectral fitting residuals were generated using the co-addition of residuals of 41 spectral fittings of Spectralon ${ }^{\circledR}$ target, 41 spectral fittings of west Pasadena target, and 40 spectral fits of the Santa Anita Park target on 3 January 2013. The systematic residuals arise from the imperfect line shape function and spectroscopic parameters in addition to uncertainties in atmospheric pressure and temperature parameters since the magnitude and positions of spiky fitting residuals consistently appear in all three target scenes. However, the magnitude of most systematic fitting residuals is within $0.5 \%$ of spectral continuum levels.

by the equation

$\sigma_{\Delta \mathrm{XGHG}}=\sqrt{\mathrm{err}_{\mathrm{MW} 1}^{2}+\operatorname{err}_{\mathrm{MW} 2}^{2}+2 \operatorname{err}_{\mathrm{MW} 1} \operatorname{err}_{\mathrm{MW} 2}}$,

where $\sigma_{\Delta \mathrm{XGHG}}$ is $1 \sigma$ standard deviation of the mean differences using two spectral regions, and $\operatorname{err}_{\mathrm{MW} 1}$ and $\operatorname{err}_{\mathrm{MW}} 2$ are the measurement uncertainties/precisions of two spectral regions. The spectral noise and the number of spectral points are the dominant factors of measurement precisions. These two factors are nearly identical between MW1 and MW2 due

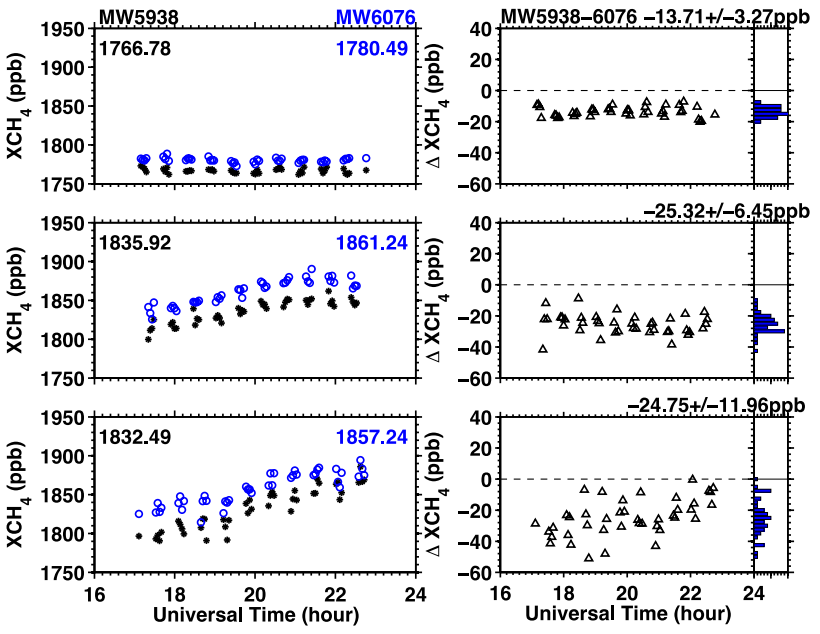

Fig. 11. $\mathrm{XCH}_{4}$ (in parts per billion (ppb)) measured by CLARSFTS with MW5938 (black dots) and MW6076 (blue circles) on 3 January 2013 (left panels), and differences of retrieved XCH4 between the two spectral regions and the histograms (right panels) in the Spectralon ${ }^{\circledR}$ viewing (top panels), towards Santa Anita Park (middle panels), and towards west Pasadena (bottom panels). Black stars in left panels: $\mathrm{XCH}_{4}$ obtained using the spectral region of MW5938. Compared to the background levels of $\mathrm{XCH}_{4}$ (top panels), $\mathrm{XCH}_{4}$ over Santa Anita Park (middle panels) and west Pasadena (bottom panels) shows higher values (mean SAP-SV: $74.95 \mathrm{ppb}$; mean WP-SV: $71.23 \mathrm{ppb}$ ) and presents stronger diurnal cycles than those measurements over the CLARS site. The $\mathrm{XCH}_{4}$ values retrieved from MW6076 are higher than those of MW5938. The mean differences between MW6076 and MW5938 are 13.71, 25.32, and $24.75 \mathrm{ppb}$ for SV, SAP and WP, respectively. These systematic differences of retrieved $\mathrm{XCH}_{4}$ values between two spectral bands likely arise from the discrepancies of spectroscopic parameters between two spectral bands and the amount/intensity of spectral features of interfering species.

to their small separations $\left(\sim 5-100 \mathrm{~cm}^{-1}\right)$ on the measured spectra and their nearly identical widths of spectral fitting windows (Table 1). The spectral noises are random, i.e., no correlation on the spectral noise between two adjacent spectral bands. Hence, the cross term in the right-hand side of Eq. (10) vanishes and Eq. (10) can be written as

$\operatorname{err}_{\mathrm{MW} 1}=\operatorname{err}_{\mathrm{MW} 2}=\sigma_{\Delta \mathrm{XGHG}} / \sqrt{2}$ 

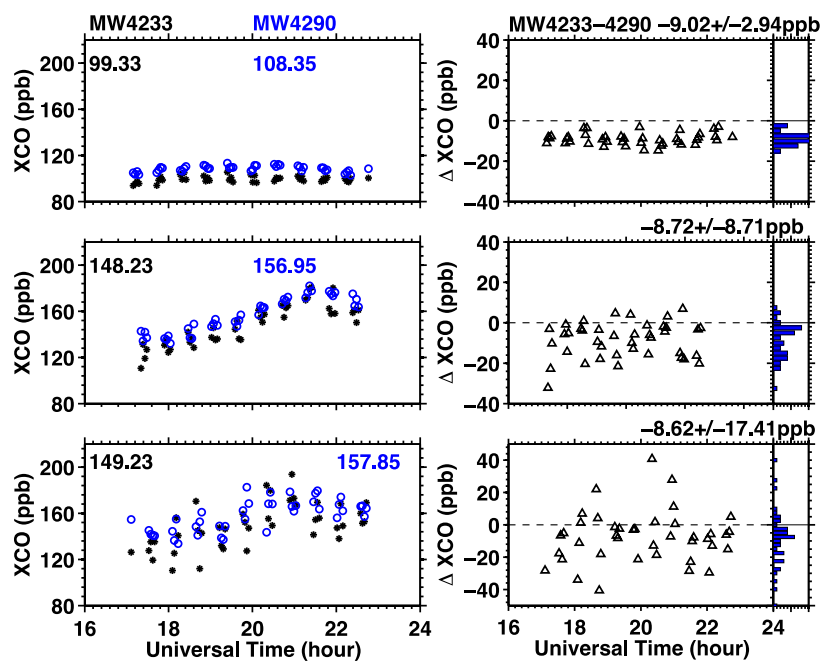

Fig. 12. XCO (in parts per billion (ppb)) measured by CLARSFTS with MW4233 (black dots) and MW4290 (blue circles) on 3 January 2013 (left panels), and differences of retrieved XCO between the two spectral regions and the histograms (right panels) in the Spectralon ${ }^{\circledR}$ viewing (top panels), towards Santa Anita Park (middle panels), and towards west Pasadena (bottom panels). Compared to the background levels of XCO (top panels), XCO over Santa Anita Park (middle panels) and west Pasadena (bottom panels) shows higher values (mean SAP-SV: 48.75 ppb; mean WP-SV: $49.70 \mathrm{ppb}$ ) and presents stronger diurnal cycles than those measurements over the CLARS site. The XCO values retrieved from MW4290 are higher than those of MW4233. The mean differences between MW4290 and MW4233 are 9.02, 8.72, and $8.62 \mathrm{ppb}$ for SV, SAP, and WP, respectively. These systematic differences of retrieved XCO values between two spectral bands have likely arisen from the discrepancies of spectroscopic parameters between two spectral bands and the amount/intensity of spectral features of interfering species.

Table 2 lists the estimated measurement precisions of $\mathrm{XCO}_{2}$, $\mathrm{XCH}_{4}$, and $\mathrm{XCO}$ over the CLARS site, Santa Anita Park and west Pasadena targets by applying Eq. (11) to the XGHG differences using two adjacent spectral regions (right panels in Figs. 7, 11, 12 and Supplement Figs. S4, S8, $\mathrm{S} 11)$. The measurements of Spectralon ${ }^{\circledR}$ targets on 3 January 2013 show higher precision $\left(\mathrm{XCO}_{2}: 0.09 \%\right.$; $\mathrm{XCH}_{4}$ : $0.13 \%$; XCO: $2.00 \%$ ) than the measurements over Santa Anita Park $\left(\mathrm{XCO}_{2}: 0.14 \% ; \mathrm{XCH}_{4}: 0.25 \%\right.$; XCO: $\left.4.01 \%\right)$ and west Pasadena targets $\left(\mathrm{XCO}_{2}: 0.24 \% ; \mathrm{XCH}_{4}: 0.46 \%\right.$; XCO: $8.01 \%)$. The measurement precision on 18 January 2013 shows characteristics similar to those on 3 January 2013. The low precision of XCO arises from the decreased spectral SNR in the spectral regions used in the measurements of CO slant column densities. The measurement precision shows target site dependence due to the differences of spectral SNR over three target sites. Overall, the high precision of CLARS-FTS measurements is sufficient to capture the diurnal variations of $\mathrm{XCO}_{2}, \mathrm{XCH}_{4}$ and $\mathrm{XCO}$ and the differences among different targets over the LA basin.

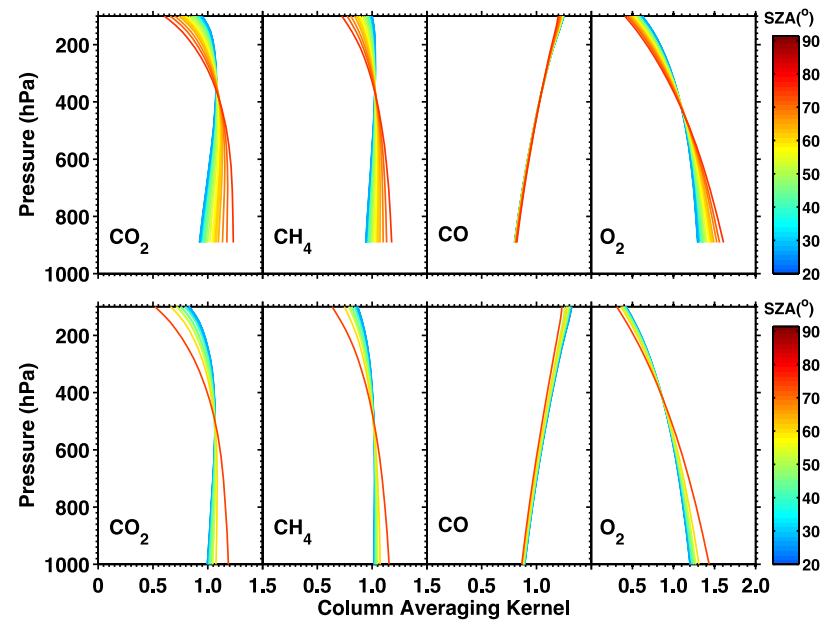

Fig. 13. Column-averaging kernels of GHG measurements using CLARS-FTS with a maximum optical path difference (MOPD) of $5 \mathrm{~cm}$. Top panels: for the measurements over the CLARS site in the Spectralon ${ }^{\circledR}$ viewing; bottom panels: for the measurements targeting the land surface of Santa Anita Park $\left(34.141^{\circ} \mathrm{N}, 118.042^{\circ} \mathrm{W}\right.$, $155 \mathrm{~m}$ above sea level, $9.3 \mathrm{~km}$ slant distance to the CLARS site), Arcadia, California.

\subsubsection{Estimation of XGHG measurement accuracy}

Systematic error sources include the uncertainties in spectroscopic line parameters, light path calculation uncertainties, and errors in the ILS, which affects the accuracy of CLARS-FTS measurements. Table 3 lists the estimated measurement accuracy. The uncertainties of measured $\mathrm{XCO}_{2}$, $\mathrm{XCH}_{4}$ and $\mathrm{XCO}$ arise from spectroscopic parameters, which are expected to be similar to those from previous studies (Washenfelder et al., 2006; Wunch et al., 2010, 2011). Regular $\mathrm{HCl}$ cell and infrared laser measurements are carried out to assess the alignment stability and performance of the FTS. The uncertainties in the light path computation arise from residual pointing errors and from the neglect of aerosol scattering in the radiative transfer calculations. As discussed previously, aerosol interference is reduced by using the simultaneously measured $\mathrm{O}_{2}$ slant column density, which is proportional to the optical path length, to compute XGHG (Sect. 4.3).

Direct validation measurements of the CLARS-FTS retrievals by independent method(s) would usefully complement the assessments of data precision and accuracy given in Tables 2 and 3. Wunch et al. (2010) used in situ aircraft measurements from the surface to high altitude along the line of sight to calibrate the measurements from four TCCON stations against World Meteorological Organization (WMO) standards. A similar approach could be applied, in principle, to the CLARS-FTS measurements, but the additional optical path from the surface to the measurement site complicates this approach. Independent measurements 
Table 3. Estimated measurement accuracy ${ }^{\mathrm{a}}$.

\begin{tabular}{lrrr}
\hline Error sources & $\mathrm{XCO}_{2}$ & $\mathrm{XCH}_{4}$ & $\mathrm{XCO}$ \\
\hline Spectroscopic line parameters, pressure, temperature profiles $^{\mathrm{b}}$ & $\sim 1.1 \%$ & $\sim 4.0 \%$ & $\sim 2.0 \%$ \\
Light path calculation $^{\mathrm{c}}$ & $<1.0 \%$ & $<1.0 \%$ & $<1.0 \%$ \\
Instrument line shape $^{\mathrm{d}}$ & $<1.0 \%$ & $<1.0 \%$ & $<1.0 \%$ \\
Total uncertainty from all error sources & $<3.1 \%$ & $<6.0 \%$ & $<4.0 \%$ \\
\hline
\end{tabular}

${ }^{\mathrm{a}}$ The discussion of measurement accuracy estimation is introduced in Sect. 4.5.2. ${ }^{\mathrm{b}}$ Based on the uncertainty of TCCON measurements prior to applying calibration factors (Wunch et al., 2010, 2011). ${ }^{\mathrm{c}}$ Refer to the measured XGHG uncertainty arising from the remaining impacts of aerosol that were not removed by the approach of computing XGHG in Sect. 4.3. ${ }^{\mathrm{d}}$ Refer to the differences between measured and theoretical line shape functions in Sect. 2.2.4.

that would meet the accuracy requirements of CLARSFTS validation/calibration are not currently available but are planned for the future.

\section{Future developments}

Several improvements will be incorporated into future versions of the CLARS-FTS retrieval algorithm. These include (1) incorporation of a more advanced radiative transfer model which accounts explicitly for aerosol scattering to retrieve aerosol properties and for more robust data filtering (absolute radiometric calibration of the FTS is being implemented to make use of this approach); (2) fine adjustment of target coordinates and the pointing system model to improve geolocation; (3) incorporation of line mixing and improved spectral line parameters to reduce systematic errors in the fitting residuals; and (4) calibration of $\mathrm{XCO}_{2}, \mathrm{XCH}_{4}$, and $\mathrm{XCO}$ retrievals using aircraft and balloon in situ profiles traceable to WMO standards.

\section{Conclusions}

We have developed an automated atmospheric observatory to measure the GHG emissions over Los Angles basin, California. Near-infrared solar absorption spectra have been acquired continuously since May 2010. The slant column densities of $\mathrm{GHG}$ and $\mathrm{O}_{2}$, which were obtained from spectral fits, were utilized to compute the column-averaged GHG VMR $\left(\mathrm{XCO}_{2}, \mathrm{XCH}_{4}\right.$, and $\left.\mathrm{XCO}\right)$. The quality of spectral fits and the measurement precisions are estimated using the measurements on 3 and 18 January 2013 under clear-sky conditions. The spectral fitting residuals of individual spectral segments were dominated by the random noise, with RMS of fitting residuals being better than $0.3 \%$ and $0.5 \%$ for the measurements above CLARS site and LA basin targets. The systematic fitting residuals are less than $0.5 \%$. They are attributed to uncertainties in the GHG spectroscopic line strengths and air-broadened width parameters and uncertainties in the diskintegrated solar spectra. Compared to the background levels, $\mathrm{XCO}_{2}$ over Santa Anita Park and west Pasadena shows higher values (6.26 ppm and $6.11 \mathrm{ppm})$ and presents stronger diurnal cycles than those measurements over the CLARS site. The precisions of retrieved $\mathrm{XCO}_{2}, \mathrm{XCH}_{4}$, and $\mathrm{XCO}$ over the CLARS site are $0.09,0.14$ and $1.94 \%$, respectively. For the measurements over LA basin targets (Santa Anita Park and west Pasadena), the precisions of retrieved $\mathrm{XCO}_{2}$, $\mathrm{XCH}_{4}$, and $\mathrm{XCO}$ are 0.16 and $0.22 \%, 0.26$ and $0.48 \%$, and 4.10 and $8.04 \%$, respectively. The high measurement precisions of CLARS-FTS provide the capabilities of capturing the diurnal variations of $\mathrm{XCO}_{2}, \mathrm{XCH}_{4}$, and $\mathrm{XCO}$ over LA basin targets and the differences among the LA basin targets. The calibration of $\mathrm{XCO}_{2}, \mathrm{XCH}_{4}$, and $\mathrm{XCO}$ retrievals using aircraft in situ profiles will be accomplished in the near future.

\section{Supplementary material related to this article is available online at http://www.atmos-meas-tech.net/7/ 713/2014/amt-7-713-2014-supplement.pdf.}

Acknowledgements. We are grateful to K. Bowman, A. Butz, R. Duren, A. Eldering, C. Frankenberg, F. Hase, E. Kort, K. F. Li, C. Miller, D. Natzic, S. Newman, C. Roehl, R. L. Shia, J. Stutz, P. Wennberg, J. Worden, D. Wunch and Y. L. Yung for many helpful discussions. Support from the NASA Instrument Incubator Program, NOAA Climate Program, NIST, California Air Resources Board and the JPL Earth Science and Technology Directorate is gratefully acknowledged. Copyright 2013, California Institute of Technology. Government sponsorship acknowledged.

Edited by: J. Notholt

\section{References}

Bekker, D. L., Lukowiak, M., Shaaban, M., Blavier, J.-F. L., and Pingree, P. J.: A Hybrid-FPGA System for On-Board Data Processing Targeting the MATMOS FTIR Instrument, Aerospace Conference Proceedings, 2008 IEEE, Vol. 1, 115, doi:10.1109/AERO.2008.4526400, Big Sky, Montana, 18 March, 2008.

Bekker, D. L., Blavier, J.-F. L., Toon, G. C., and Servais C.: An FPGA-based Data Acquisition and Processing 
System for the MATMOS FTIR Instrument, Aerospace Conference Proceedings, 2009 IEEE, Vol. 1, 1-11, doi:10.1109/AERO.2009.4839459, Big Sky, Montana, 714 March, 2009.

Bekker, D. L., Blavier, J. L., Fu, D., Key, R. W., Manatt, K. S., McKinney, C., Rider, D. M., Sander, S. P., Werne, T. A., Wu, A. C., and Wu, Y. H.: Command and data handling system for the panchromatic Fourier transform spectrometer, Aerospace Conference Proceedings, 2012 IEEE, Vol. 1, 110, doi:10.1109/AERO.2012.6187224, Big Sky, Montana, 310 March, 2012.

Bergland, G.: A radix-eight fast Fourier transform subroutine for real-valued series, IEEE Transactions on Audio and Electroacoustics, 17, 138-144, 1969.

Brasunas, J. C. and Cushman, G. M.: Uniform Time sampling Fourier Transform Spectroscopy, Appl. Optics, 36, 2206-2210, doi:10.1364/AO.36.002206, 1997.

Brault, J. W.: New approach to high-precision Fourier transform spectrometer design, Appl. Optics, 35, 2891-2896, doi:10.1364/AO.35.002891, 1996.

Brault, J. W., Brown, L. R., Chackerian, C., Freedman, R., PredoiCross, A., Pine, A. S.: Self-broadened ${ }^{12} \mathrm{C}^{16} \mathrm{O}$ line shapes in the $v=2 \leftarrow 0$ band, J. Mol. Spectrosc., 222, 220-239, 2003.

Brown, L. R., Benner, D. C., Champion, J. P., Devi, V. M., Fejard, L., Gamache, R. R., Gabard, T., Hilico, J. C., Lavorel, B., Loete, M., Mellau, G. C., Nikitin, A., Pine, A. S., Predoi-Cross, A., Rinsland, C. P., Robert, O., Sams, R. L., Smith, M. A. H., Tashkun, S. A., and Tyuterev, V. G.: Methane line parameters in HITRAN, J. Quant. Spectrosc. Ra., 82, 219-38, 2003.

Campbell, J.: Synthetic quadrature phase detector/demodulator for Fourier transform spectrometers, Appl. Optics, 47, 6889-6894, 2008.

Connes, J.: Recherches sur la spectroscopie par transformation de Fourier, Revue d'Optique, 40, 45-79, 116-140, 171-190, 231265, 1961.

Croes, B. E.: New Directions: California's programs for improving air quality and minimizing greenhouse gas emissions, Atmos. Environ., 47, 562-563, doi:10.1016/j.atmosenv.2010.05.041, 2012.

Davis, S. P., Abrams, M. C., and Brault, J. W.: Fourier Transform Spectrometry, 2nd Edn., Academic Press, San Diego, California, 2001.

Fishman, J., Iraci, L. T., Al-Saadi, J., Chance, K., Chavez, F., Chin, M., Coble, P., Davis, C., DiGiacomo, P. M., Edwards, D., Eldering, A., Goes, J., Herman, J., Hu, C., Jacob, D., Jordan, C., Kawa, S. R., Key, R., Liu, X., Lohrenz, S., Mannino, A., Natraj, V., Neil, D., Neu, J., Newchurch, M., Pickering, K., Salisbury, J., Sosik, H., Subramaniam, A., Tzortziou, M., Wang, J., and Wang, M.: The United States' next generation of atmospheric composition and coastal ecosystem measurements: NASA's Geostationary Coastal and Air Pollution Events (GEO-CAPE) mission, B. Am. Meteorol. Soc., 93, 1547-1566, doi:10.1175/BAMS-D-1100201.1, 2012.

Forman, M. L., Steel, W. H., and Vanasse, G. A.: Correction of asymmetric interferograms obtained in Fourier spectroscopy, J. Opt. Soc. Am., 56., 59-63, doi:10.1364/JOSA.56.000059, 1966.

Frankenberg, C., Warneke, T., Butz, A., Aben, I., Hase, F., Spietz, P., and Brown, L. R.: Pressure broadening in the $2 v_{3}$ band of methane and its implication on atmospheric retrievals, At- mos. Chem. Phys., 8, 5061-5075, doi:10.5194/acp-8-5061-2008, 2008.

Fu, D., Sung, K., Boone, C. D., Walker, K. A., and Bernath, P. F.: Ground-based solar absorption studies for the Carbon Cycle science by Fourier Transform Spectroscopy (CC-FTS) mission, J. Quant. Spectrosc. Ra., 109, 2219-2243, 2008.

Geller, M.: A high resolution atlas of the infrared spectrum of the Sun and the Earth atmosphere from space, Vol. III, Key to identification of solar features from 650 to $4800 \mathrm{~cm}^{-1}$, NASA Reference Publication 122, NASA: Washington, DC, USA, 1992.

Geller, M.: Line identification in ATMOS solar spectra, in: Laboratory and Astronomical High Resolution Spectra, Proceedings of ASP Conference No. 81, Brussels, Belgium, 29 August2 September 1994, ASP Conference Series, edited by: Sauval, A. J., Blomme, R., and Grevesse, N., Astronomical Society of the Pacific: San Francisco, CA, USA, p. 81, 1995.

Griesmann, U., Kling, R., Burnett, J. H., and Bratasz, L.: The NIST FT700 Vacuum Ultraviolet Fourier Transform Spectrometer: applications in ultraviolet spectrometry and radiometry, Proc. SPIE 3818, 180-188, 1999.

Griffiths, P. R. and De Haseth, J. A.: Fourier Transform Infrared Spectrometry, second edition, Wiley-Interscience, 2007.

Gordon, I. E., Kassi, S., Campargue, A., and Toon G. C.: First identification of the $a^{1} \Delta_{g}-X^{3} \sum_{g}-$ electric quadrupole transitions of oxygen in solar and laboratory spectra, J. Quant. Spectrosc. Ra., 111, 1174-1183, 2010.

Hase, F., Blumenstock, T., and Paton-Walsh, C.: Analysis of instrumental line shape of high-resolution FTIR-spectrometers using gas cell measurements and a new retrieval software, Appl. Optics, 38, 3417-3422, 1999.

Hoornweg, D., Freire, M., Lee, M. J., Bhada-Tata, P., and Yuen, B.: Cities and Climate Change: An Urgent Agenda, The World Bank, Washington, D. C., 2010.

Irion, F. W., Gunson, M. R., Toon, G. C., Chang, A. Y., Eldering, A., Mahieu, E., Manney, G. L., Michelsen, H. A., Moyer, E. J., Newchurch, M. J., Osterman, G. B., Rinsland, C. P., Salawitch, R. J., Sen, B., Yung, Y. L., and Zander, R.: Atmospheric Trace Molecule Spectroscopy (ATMOS) Experiment Version 3 data retrievals, Appl. Optics, 41, 6968-6979, 2002.

Jenouvrier, A., Daumont, L., Regalia-Jarlot, L., Tyuterev, V. G., Carleer, M., Vandaele, A. C., Mikhailenko, S., and Fally, S. Fourier transform measurements of water vapor line parameters in the $4200-6600 \mathrm{~cm}^{-1}$ region, J. Quant. Spectrosc. Ra., 105, 326-355, doi:10.1016/j.jqsrt.2006.11.007, 2007.

Keppel-Aleks, G., Toon, G. C., Wennberg, P. O., and Deutscher, N. M.: Reducing the impact of source brightness fluctuations on spectra obtained by Fourier-transform spectrometry, Appl. Optics, 46, 4774-4779, doi:10.1364/AO.46.004774, 2007.

Key, R., Sander, S., Eldering, A., Rider, D., Blavier, J.-F., Bekker, D., Wu, Y.-H., and Manatt, K.: The Geostationary Fourier Transform Spectrometer, Aerospace Conference Proceedings, 310 March 2012 IEEE, doi:10.1109/AERO.2012.6187164, Big Sky, Montana, 2012.

Kort, E. A., Frankenberg, C., Miller, C. E., and Oda, T.: Space-based observations of megacity carbon dioxide, Geophys. Res. Lett., 39, L17806, doi:10.1029/2012GL052738, 2012.

Livingston, W. and Wallace, L.: An atlas of the solar spectrum in the infrared from 1,850 to $9,000 \mathrm{~cm}^{-1}(1.1$ to $5.4 \mu \mathrm{m})$, NSO Technical Report, NSO: Tucson, AZ, USA, 1991. 
Manning, C. J. and Combs, R. J.: FT-IR Interferogram sampling validation and correction, Proc. SPIE, Electro-Optic, Integrated Optic, and Electronic Technologies for Online Chemical Process Monitoring with Advanced Techniques, 3537, 181-186, 1999.

McKain, K., Wofsy, S. C., Nehrkorn, T., Eluszkiewicz, J., Ehleringer, J. R., and Stephens, B. B.: Assessment of groundbased atmospheric observations for verification of greenhouse gas emissions from an urban region, P. Natl. Acad. Sci., 109, 8423-8428, doi:10.1073/pnas.1116645109, 2012.

National Research Council, Committee on Earth Science and Applications from Space: A community assessment and strategy for the future: Earth science and applications from space: national imperatives for the next decade and beyond, National Academies Press, Washington D.C., 2007.

Newman, S. M., Lane, I. C., Orr-Ewing, A. J., Newnham, D. A., and Ballard, J.: Integrated absorption intensity and Einstein coefficients for the $\mathrm{O}_{2} a^{1} \Delta_{g}-X^{3} \Sigma_{g}-(0,0)$ transition: A comparison of cavity ring down and high resolution Fourier transform spectroscopy with a long-path absorption cell, J. Chem. Phys. 110, 10749-10757, doi:10.1063/1.479018, 1999.

Norton, R. H. and Rinsland, C. P.: ATMOS data processing and science analysis methods, Appl. Optics, 30, 389-400, 1991.

O’Dell, C. W., Connor, B., Bösch, H., O’Brien, D., Frankenberg, C., Castano, R., Christi, M., Eldering, D., Fisher, B., Gunson, M., McDuffie, J., Miller, C. E., Natraj, V., Oyafuso, F., Polonsky, I., Smyth, M., Taylor, T., Toon, G. C., Wennberg, P. O., and Wunch, D.: The $\mathrm{ACOS} \mathrm{CO}_{2}$ retrieval algorithm - Part 1: Description and validation against synthetic observations, Atmos. Meas. Tech., 5, 99-121, doi:10.5194/amt-5-99-2012, 2012.

Olsen, S. C. and Randerson, J. T.: Differences between surface and column atmospheric $\mathrm{CO}_{2}$ and implications for carbon cycle research, J. Geophys. Res., 109, D02301, doi:10.1029/2003JD003968, 2004.

Pingree, P. J., Blavier, J.-F. L., Toon, G. C., and Bekker, D. L.: An FPGA/SoC approach to on-board data processing enabling new Mars science with smart payloads, Aerospace Conference Proceedings, 3-10 March 2007 IEEE, Vol. 1, 1-12, doi:10.1109/AERO.2007.353091, Big Sky, Montana, 2007.

Pougatchev, N. S., Campbell, J. F., Regan, C. R., Abrams, M. C., Brault, J. W., Farmer, C. B., and Hinton, D. E.: Advanced technologies high resolution Fourier transform spectrometer for atmospheric studies, Aerospace Conference Proceedings, 18-25 March 2000 IEEE, Vol. 3, 237-243, doi:10.1109/AERO.2000.879851, Big Sky, Montana, 2000.

Rothman, L. S., Gordon I. E., Barbe, A., Benner, C. D., Bernath, P. F., Birk, M., Boudon, V., Brown, L. R., Campargue, A., Champion, J.-P., Chance, K., Coudert, L. H., Dana, V., Devi, V. M., Fally, S., Flaud, J.-M., Gamache, R. R., Goldman, A., Jacquemart, D., Kleiner, I., Lacome, N., Lafferty, W. J., Mandin, J.Y., Massie, S. T., Mikhailenko, S. N., Miller, C. E., MoazzenAhmadi, N., Naumenko, O. V., Nikitin, A. V., Orphal, J., Perevalov, V. I., Perrin, A., Predoi-Cross, A., Rinsland, C. P., Rotger, M., Šimečková, M., Smith, M. A. H., Sung, K., Tashkun, S. A., Tennyson, J., Toth, R. A., Vandaele, A. C., and Vander Auwera, J.: The HITRAN 2008 molecular spectroscopic database, J. Quant. Spectrosc. Ra., 110, 533-572, 2009.

Sen, B., Osterman, G. B., Salawitch, R. J., Toon, G. C., Margitan, J. J., Blavier, J.-F., Chang, A. Y., May, R. D., Webster, C. R., Stimpfle, R. M., Bonne, G. P., Voss, P. B., Perkins, K. K., Ander- son, J. G., Cohen, R. C., Elkins, J. W., Dutton, G. S., Hurst, D. F., Romashkin, P. A., Atlas, E. L., Schauffler, S. M., and Loewenstein, M.: The budget and partitioning of stratospheric chlorine during the 1997 Arctic summer, J. Geophys. Res., 104, 26653 $26665,1999$.

Smith, K. M. and Newnham, D. A.: Near-infrared absorption cross sections and integrated absorption intensities of molecular oxygen $\left(\mathrm{O}_{2}, \mathrm{O}_{2}-\mathrm{O}_{2}\right.$, and $\left.\mathrm{O}_{2}-\mathrm{N}_{2}\right)$, J. Geophys. Res., 105, 7383-7396, 2000.

Toth, R. A.: Line positions and strengths of $\mathrm{N}_{2} \mathrm{O}$ between 3515 and $7800 \mathrm{~cm}^{-1}$, J. Mol. Spectrosc., 197, 158-87, 1999.

Toth, R. A.: $\mathrm{N}_{2}$ and air-broadened linewidths and frequency-shifts of $\mathrm{N}_{2} \mathrm{O}$, J. Quant. Spectrosc. Ra., 66, 285-304, 2000.

Toth, R. A.: Measurements of positions, strengths and selfbroadened widths of $\mathrm{H}_{2} \mathrm{O}$ from 2900 to $8000 \mathrm{~cm}^{-1}$ : line strength analysis of the 2nd triad bands, J. Quant. Spectrosc. Ra., 94, 51107, 2005.

Toth, R. A., Brown, L. R., Miller, C. E., Malathy Devi, V., and Benner, D. C.: Spectroscopic database of $\mathrm{CO}_{2}$ line parameters: $4300-7000 \mathrm{~cm}^{-1}$, J. Quant. Spectrosc. Ra., 109, 906-921, doi:10.1016/j.jqsrt.2007.12.004, 2008

Yang, Z., Wennberg, P. O., Cageao, R. P., Pongetti, T. J., Toon, G. C., and Sander, S. P.: Ground-based photon path measurements from solar absorption spectra of the $\mathrm{O}_{2}$ A-band, J. Quant. Spectrosc. Ra., 90, 309-321, doi:10.1016/j.jqsrt.2004.03.020, 2005.

Wallace, L., Hinkle, K., and Livingston, W. C.: An Atlas of the Photospheric Spectrum from 8,900 to $13,600 \mathrm{~cm}^{-1}$ (7350 to $11230 \AA$ Å), NSO Technical Report, NSO: Tucson, AZ, USA, 1993.

Washenfelder, R. A., Toon, G. C., Blavier, J. F., Yang, Z., Allen, N. T., Wennberg, P. O., Vay, S. A., Matross, D. M., and Daube, B. C.: Carbon dioxide column abundances at the Wisconsin Tall Tower site, J. Geophys. Res. 111, D22305, doi:10.1029/2006JD007154, 2006.

Weather Underground web site: available at: http://www. wunderground.com/weatherstation/WXDailyHistory.asp? ID=KCAMOUNT11, last access: 8 January 2014.

Wunch, D., Wennberg, P. O., Toon, G. C., Keppel-Aleks, G., and Yavin, Y. G.: Emissions of greenhouse gases from a North American megacity, Geophys. Res. Lett., 36, L15810, doi:10.1029/2009GL039825, 2009.

Wunch, D., Toon, G. C., Wennberg, P. O., Wofsy, S. C., Stephens, B. B., Fischer, M. L., Uchino, O., Abshire, J. B., Bernath, P., Biraud, S. C., Blavier, J.-F. L., Boone, C., Bowman, K. P., Browell, E. V., Campos, T., Connor, B. J., Daube, B. C., Deutscher, N. M., Diao, M., Elkins, J. W., Gerbig, C., Gottlieb, E., Griffith, D. W. T., Hurst, D. F., Jiménez, R., Keppel-Aleks, G., Kort, E. A., Macatangay, R., Machida, T., Matsueda, H., Moore, F., Morino, I., Park, S., Robinson, J., Roehl, C. M., Sawa, Y., Sherlock, V., Sweeney, C., Tanaka, T., and Zondlo, M. A.: Calibration of the Total Carbon Column Observing Network using aircraft profile data, Atmos. Meas. Tech., 3, 1351-1362, doi:10.5194/amt3-1351-2010, 2010.

Wunch, D., Toon, G. C. , Blavier, J.-F. L., Washenfelder, R. A., Notholt, J., Connor, B. J., Griffith, D. W. T., Sherlock, V., and Wennberg, P. O.: The total carbon column observing network, Philos. T. Roy. Soc. A, 369, 2087-2112, doi:10.1098/rsta.2010.0240, 2011. 